\title{
Convergence of decreasing male and increasing female incidence rates in major tobacco-related cancers in Europe in $1988-2010$
}

\author{
Joannie Lortet-Tieulent ${ }^{\mathrm{a}, \mathrm{b}}$, Elisenda Renteria ${ }^{\mathrm{a}}$, Linda Sharp ${ }^{\mathrm{c}}$, \\ Elisabete Weiderpass ${ }^{\text {d,e,f,g }}$, Harry Comber ${ }^{\mathrm{c}}$, Paul Baas ${ }^{\mathrm{h}}$, Freddie Bray ${ }^{\mathrm{a}}$, \\ Jan Willem Coebergh ${ }^{\mathrm{i}, \mathrm{j}}$, Isabelle Soerjomataram ${ }^{\mathrm{a}, *}$
}

\author{
${ }^{\text {a }}$ Section of Cancer Information, International Agency for Research on Cancer, Lyon, France \\ ${ }^{\mathrm{b}}$ Surveillance \& Health Services Research, American Cancer Society, Atlanta, United States \\ ${ }^{\mathrm{c}}$ National Registry of Ireland, Cork, Ireland \\ d Department of Community Medicine, Faculty of Health Sciences, UiT The Arctic University of Norway, Tromsø, Norway \\ ${ }^{\mathrm{e}}$ Department of Research, Cancer Registry of Norway, Oslo, Norway \\ ${ }^{\mathrm{f}}$ Department of Medical Epidemiology and Biostatistics, Karolinska Institutet, Stockholm, Sweden \\ ${ }^{\mathrm{g}}$ Samfundet Folkhälsan, Helsinki, Finland \\ ${ }^{\mathrm{h}}$ Department of Thoracic Oncology, The Netherlands Cancer Institute, Amsterdam, The Netherlands \\ ${ }^{\mathrm{i}}$ Erasmus University Medical Centre, Department of Public Health, Rotterdam, The Netherlands \\ ${ }^{\mathrm{j}}$ Eindhoven Cancer Registry, Comprehensive Cancer Centre South, Eindhoven, The Netherlands
}

\section{KEYWORDS \\ Lung cancer \\ Laryngeal cancer \\ Oral cancer \\ Oesophageal cancer \\ Pharyngeal cancer \\ Incidence \\ Tobacco \\ Trends \\ Europe \\ Registries}

\begin{abstract}
Introduction: Smoking prevalence has been declining in men all over Europe, while the trend varies in European regions among women. To study the impact of past smoking prevalence, we present a comprehensive overview of the most recent trends in incidence, during 1988-2010, in 26 countries, of four of the major cancers in the respiratory and upper gastro-intestinal tract associated with tobacco smoking.

Methods: Data from 47 population-based cancer registries for lung, laryngeal, oral cavity and pharyngeal, and oesophageal cancer cases were obtained from the newly developed data repository within the European Cancer Observatory (http://eco.iarc.fr/). Truncated agestandardised incidence rates (35-74 years) by calendar year, average annual percentage change in incidence over 1998-2007 were calculated. Smoking prevalence in selected countries was extracted from the Organisation for Economic Co-operation and Development and the World Health Organization databases.

Results: There remained great but changing variation in the incidence rates of tobacco-related cancers by European region. Generally, the high rates among men have been declining, while the lower rates among women are increasing, resulting in convergence of the rates. Female lung
\end{abstract}

\footnotetext{
* Corresponding author: Address: Section of Cancer Information, International Agency for Research on Cancer, 150 Cours Albert Thomas, 69008 Lyon, France. Tel./fax: $+33(0) 472738189$.

E-mail address: SoerjomataramI@iarc.fr (I. Soerjomataram).
} 
cancer rates were above male rates in Denmark, Iceland and Sweden (35-64 years). In lung and laryngeal cancers, where smoking is the main risk factor, rates were highest in central and eastern Europe, southern Europe and the Baltic countries. Despite a lowering of female smoking prevalence, female incidence rates of lung, laryngeal and oral cavity cancers increased in most parts of Europe, but were stable in the Baltic countries. Mixed trends emerged in oesophageal cancer, probably explained by differing risk factors for the two main histological subtypes.

Conclusions: This data repository offers the opportunity to show the variety of incidence trends by sex among European countries. The diverse patterns of trends reflect varied exposure to risk factors. Given the heavy cancer burden attributed to tobacco and the fact that tobacco use is entirely preventable, tobacco control remains a top priority in Europe. Prevention efforts should be intensified in central and eastern Europe, southern Europe and the Baltic countries. (c) 2013 Elsevier Ltd. All rights reserved.

\section{Introduction}

Tobacco was introduced into Europe by Spanish explorers returning from the Americas in the late fifteenth century. By the late nineteenth century, tobacco was being widely used by men in Europe [1], first in the forms of pipe-, cigar-smoking and snuff-taking. Then, after mass production became possible at the end of the nineteenth century, cigarettes, strongly promoted by advertising and marketing efforts, became

Table 1

Populations studied by country $(N=26)$, study period, population covered by the registration area and proportion of the national population covered by the 47 national or regional studied registries.

\begin{tabular}{|c|c|c|c|c|}
\hline Region & Countries & Years & $\begin{array}{l}2007 \text { Population in the studied registries } \\
\text { (thousands) }\end{array}$ & $\begin{array}{l}\text { Proportion of the national population covered } \\
(\%)\end{array}$ \\
\hline \multicolumn{5}{|c|}{ Central \& eastern Europe } \\
\hline & Belarus & $1988-2007$ & 9,702 & 100 \\
\hline & Bulgaria & 1993-2008 & 7,660 & 100 \\
\hline & Czech Republic & $1988-2008$ & 10,323 & 100 \\
\hline & Poland $^{\mathrm{a}}$ & $1988-2008$ & 2,042 & 5.2 \\
\hline & Russian & 1993-2008 & 142,115 & 100 \\
\hline & Federation & & & \\
\hline & Slovakia & 1988-2007 & 5,398 & 100 \\
\hline \multicolumn{5}{|c|}{ Northern Europe } \\
\hline & Denmark & 1988-2010 & 5,461 & 100 \\
\hline & Estonia & $1988-2007$ & 1,341 & 100 \\
\hline & Finland & $1988-2010$ & 5,289 & 100 \\
\hline & Iceland & $1988-2010$ & 311 & 100 \\
\hline & Ireland & 1994-2007 & 4,339 & 100 \\
\hline & Latvia & $1988-2007$ & 2,276 & 100 \\
\hline & Lithuania & $1988-2007$ & 3,376 & 100 \\
\hline & Norway & 1988-2009 & 4,708 & 100 \\
\hline & Sweden & 1988-2009 & 9,148 & 100 \\
\hline & United Kingdom ${ }^{\mathrm{a}}$ & $1988-2007$ & 56,236 & 88.3 \\
\hline \multicolumn{5}{|c|}{ Southern Europe } \\
\hline & Croatia & $1988-2007$ & 4,436 & 100 \\
\hline & Italy $^{\mathrm{a}}$ & 1988-2007 & 4,359 & 6.9 \\
\hline & Malta & 1992-2009 & 409 & 100 \\
\hline & Slovenia & $1988-2007$ & 2,019 & 100 \\
\hline & Spain $^{\mathrm{a}}$ & $1988-2005$ & $3,502^{\mathrm{b}}$ & 7.7 \\
\hline \multicolumn{5}{|c|}{ Western Europe } \\
\hline & Austria & 1990-2009 & 8,301 & 100 \\
\hline & France $^{\mathrm{a}}$ & 1988-2009 & 4,388 & 6.8 \\
\hline & Germany $^{\mathrm{a}}$ & $1998-2007$ & 13,888 & 16.1 \\
\hline & Switzerland $^{\mathrm{a}}$ & $1988-2008$ & 968 & 12.3 \\
\hline & The Netherlands & 1989-2008 & 16,382 & 100 \\
\hline Total & & & 328,376 & \\
\hline
\end{tabular}

${ }^{a}$ Regional registries: France (Doubs, Herault, Isere, Haut-Rhin, Somme, Tarn); Germany (Brandenburg, Hamburg, Saxony, Mecklenburg, North Rhine-Westphalia, Saarland); Poland (Kielce, Cracow); Italy (Modena, Parma, Ragusa, Romagna, Torino, Varese); Spain (Granada, Murcia, Navarra, Tarragona); Switzerland (Geneva, St Gall-Appenzell), United Kingdom (England and Scotland).

${ }^{\mathrm{b}}$ Population data from 2005. 


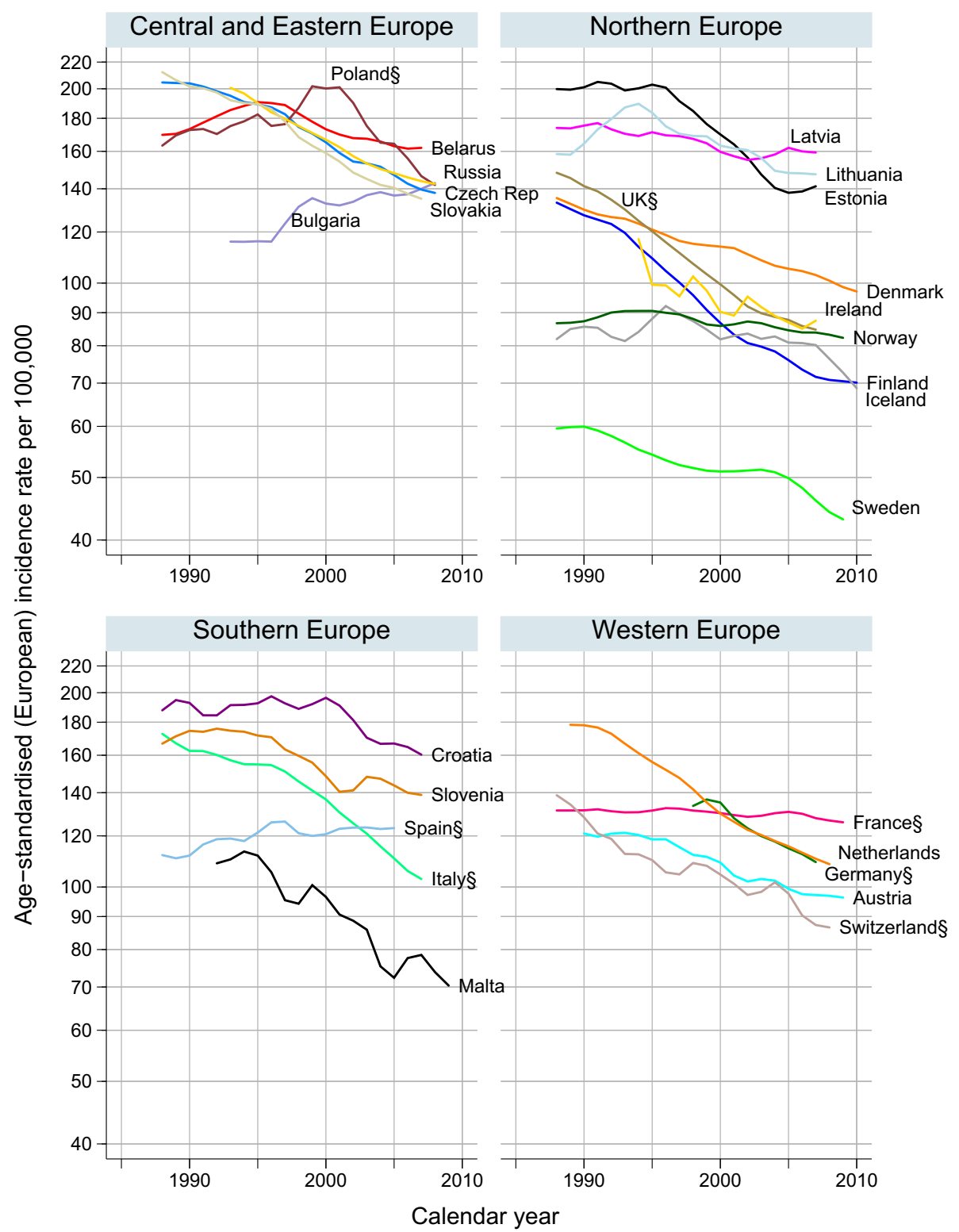

Fig. 1. Trends in lung cancer age-standardised (European) incidence in men aged 35-74 by country and region, from 1988 to the most recent year available (2005-2010). § regional registries.

the norm for tobacco consumption. From the 1930s, together with the forces of emancipation, women began adopting the habit on a large scale, first in North America and in northern and western Europe, until the 1970s. By the 1960s, the smoking prevalence in men was at least $70 \%$ in Denmark, the United Kingdom (UK) and Belgium and $90 \%$ in the Netherlands, and around 30\% in women [2]. Thereafter, the proportion of smokers rapidly decreased in men in these parts of Europe, falling to around $40-50 \%$ by 1988 . In contrast, in women, the prevalence rose gradually over time, but remained lower than in men. In southern Europe, the tobacco epidemic lagged behind that in northern and western Europe, especially in women. In Russia, a small but significant rise in the prevalence of tobacco smoking among men was reported, from $57 \%$ in 1992 to $63 \%$ in 2003 , whereas rates among women more than doubled from $7 \%$ to $15 \%$ in the same period [3]. From the mid-1990s until 2002, the prevalence of smoking among men in Estonia, Latvia and Lithuania was around 50\% (compared to 29\% in Finland), and ranged between $10 \%$ and $20 \%$ among women. Smoking increased among Lithuanian women from $6 \%$ in 1994 to $13 \%$ in 2002, but decreased among Estonian men and women [4]. Mass cigarette use followed the economic development in Europe: firstly in northern and western Europe, secondly in southern Europe, thirdly in central and eastern Europe.

Cigarette smoking is a causal agent for cancers of the oral cavity, oropharynx, nasopharynx, hypopharynx, oesophagus, stomach, colorectum, liver, pancreas, nasal 


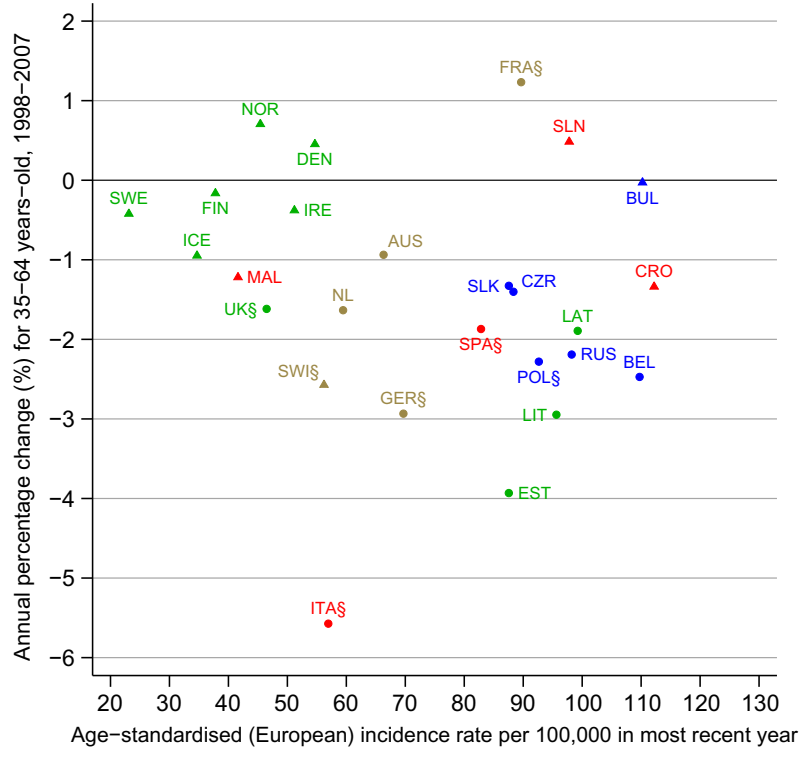

Fig. 2a. Average annual percentage change (AAPC) between 1998 and 2007 (except 1996-2005 for Spain) and age-standardised (European) incidence rates (ASR) of the most recent year (2005-2010) of lung cancer in men aged 35 to 64 . Dots indicate statistically significant AAPC $(p \leqslant 0.05)$; triangles indicate non-significant AAPC AUS Austria; BEL - Belarus; BUL - Bulgaria; CRO - Croatia; CZR Czech Republic; DEN - Denmark; EST - Estonia; FIN - Finland; FRA§ - France (regional registries); GER§ - Germany (regional registries); ICE - Iceland; IRE - Ireland; ITA§ - Italy (regional registries); LAT - Latvia; LIT - Lithuania; MAL - Malta; NOR Norway; POL $\S$ - Poland (regional registries); RUS - Russian Federation; SLK - Slovakia; SLN - Slovenia; SPA§ - Spain (regional registries); SWE - Sweden; SWI§ - Switzerland (regional registries); $\mathrm{NL}$ - The Netherlands; UK§ - United Kingdom (regional registries).

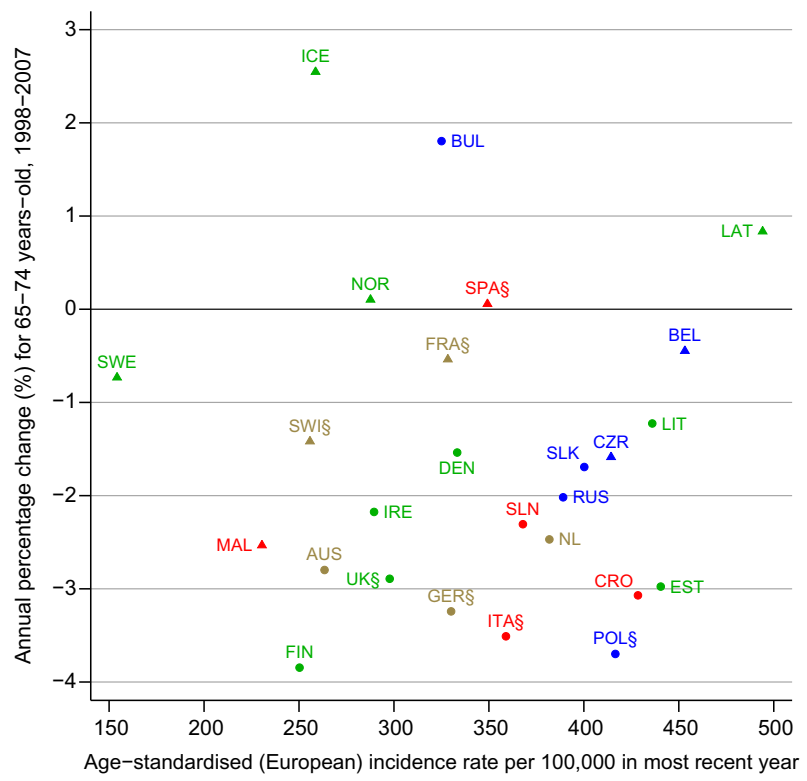

Fig. 2b. Average annual percentage change (AAPC) between 1998 and 2007 (except 1996-2005 for Spain) and age-standardised (European) incidence rates (ASR) of the most recent year of lung cancer in men aged 65 to 74 . Dots indicate statistically significant AAPC $(p \leqslant 0.05)$; triangles indicate non-significant AAPC. $\S$ Regional registries. cavity, paranasal sinuses, larynx, lung, uterine cervix, ovary, urinary bladder, kidney, ureter and bone marrow (myeloid leukaemia). Second-hand tobacco smoke and smokeless tobacco also induce cancer [5]. The European Prospective Investigation into Cancer and Nutrition Study (EPIC) calculated that among the 19 above-mentioned tobacco-related cancer cases, $35 \%$ of them were attributable to cigarette smoking $(42 \%$ in men and $23 \%$ in women) [6]. In 2012 in Europe (40 countries), there were an estimated almost 600,000 new cases of: lung $(410,000)$, oral cavity and pharyngeal $(100,000)$, oesophageal $(46,000)$ and laryngeal cancer $(40,000)$ [7], the cancers for which the fraction attributable to smoking is highest (with lower urinary tract). For each of these sites, men represented $71 \%$ to $90 \%$ of the patients.

Using high-quality population-based cancer registration data, this study aims to identify patterns in the incidence of major tobacco-related cancers (lung, laryngeal, oral cavity and oesophageal cancer), between 1988 and 2010, especially contrasting trends in men and women. We analysed data from 47 cancer registries covering 328 million inhabitants, representing 26 European countries, using age-standardised rates and average annual percentage change and compared smoking prevalence to lung cancer incidence.

\section{Methods}

Incidence data by year, 5-year age group, cancer and sex and corresponding population figures were obtained from the EUREG database, part of the European Cancer Observatory (ECO) website (http://eco.iarc.fr) [8] hosted by the International Agency for Research on Cancer (IARC). The ECO website was developed within the framework of the EUROCOURSE project to enable the rapid exploration of geographical patterns and temporal trends of incidence, mortality and survival observed in European population-based cancer registries. The cancer registries were invited to submit their data, in 2010, through a web portal. As of mid-2013, 130 of the 200 European registries had contributed.

To ensure a high level of data quality and data comparability for this study, cancer registries from the EUREG database were only included in this study if they had been published in Volume IX of Cancer Incidence in Five Continents (CI5) [9] and had available annual incidence data for at least 10 consecutive years from 1998 onwards. The rigorous process of data quality assurance in CI5 is described elsewhere [9].

To assess recent trends, the period of analysis was restricted to 1988 and thereafter.

The Malta National Cancer Registry submitted data to the EUREG database for 1994-2009. To expand the length of the study period additional data for 1992-1993 were extracted from CI5plus [10], which contains annual incidence for selected cancer registries published in CI5 


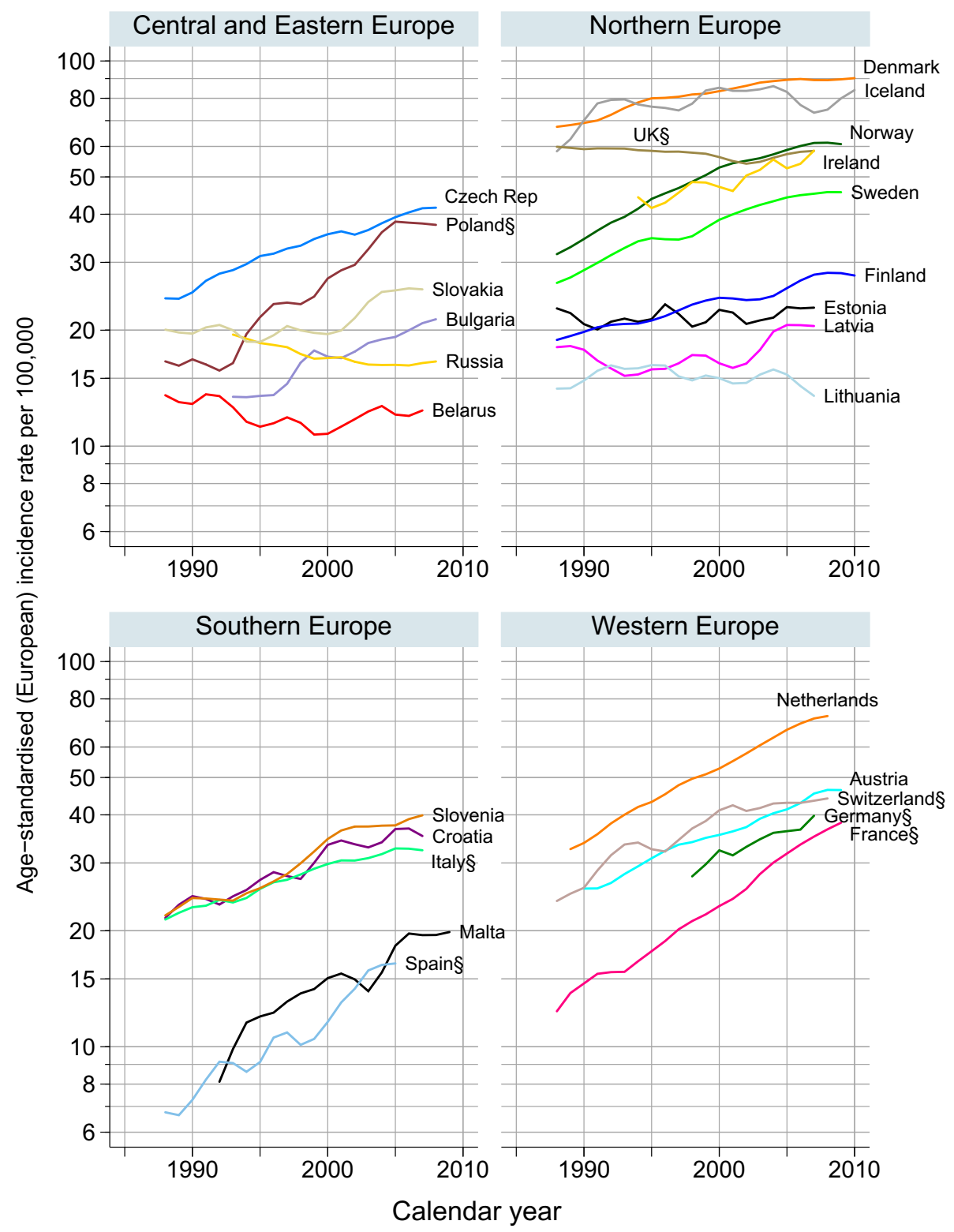

Fig. 3. Trends in lung cancer age-standardised (European) incidence in women aged 35-74 by country and region, from 1988 to the most recent year available (2005-2010). § Regional registries.

for the longest possible period. Additional Norwegian (2008-2009), Danish and Finnish (2008-2010) data were extracted from NORDCAN [11], a database maintained by the Association of the Nordic Cancer Registries. Lastly, Russian data were available through the Ministry of Health and Social Development [12], as data from the St Petersburg registry published in CI5 were only available for 1992-1997. Russia is a populous European country whose cancer trends serve as references for the other central and eastern European countries. Russian national data presented a high percentage of microscopically verified records $(>85 \%)$, acceptable for CI5 selection standards.

Finally, population-based registries from 26 European countries (Table 1) were included in this study and grouped into four regions, according to the United Nations classification [13]. Of the 26 countries, 19 had national data. For the remaining seven countries, data from regional registries were aggregated to obtain an estimate of the (unknown) national incidence (see footnote of Table 1 for the list of the regional registries). When combining regional registries, we aimed to maximise the population coverage of the country by selecting as many registries as possible that had a common registration period and which met the inclusion criteria. Unfortunately, in Italy, due to the selection process, only registries from the northern part of the country were eligible.

Of the 19 cancer sites associated with tobacco, lung and larynx were estimated to have the highest population 


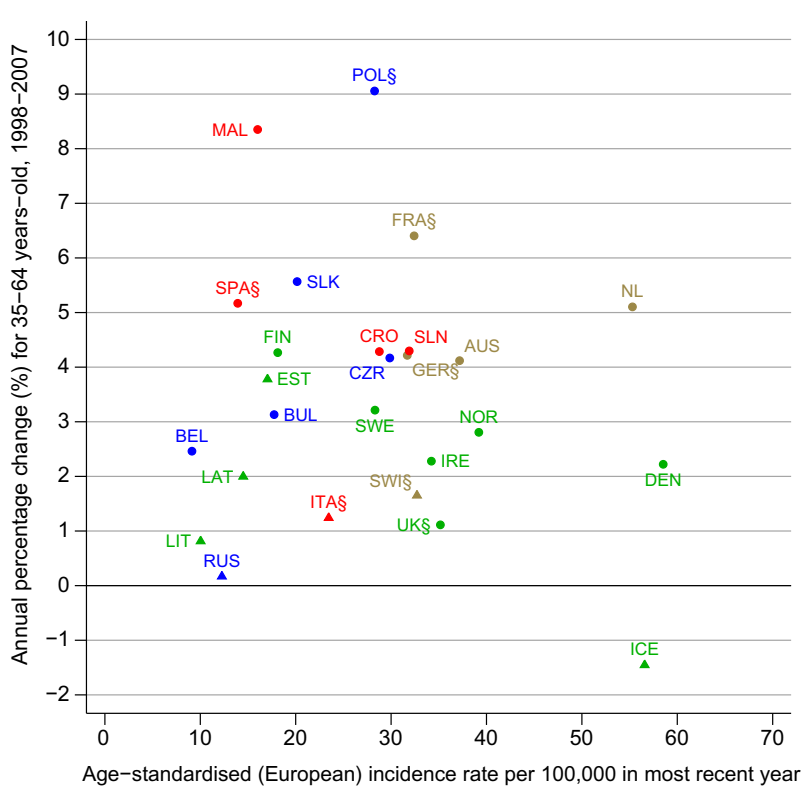

Fig. 4a. Average annual percentage change (AAPC) between 1998 and 2007 (except 1996-2005 for Spain) and age-standardised (European) incidence rates (ASR) of the most recent year of lung cancer in women aged 35 to 64 . Dots indicate statistically significant AAPC $(p \leqslant 0.05)$; triangles indicate non-significant AAPC. Colours indicate European regions: Central and eastern (blue), northern (green), southern (red) and western (brown). § Regional registries.

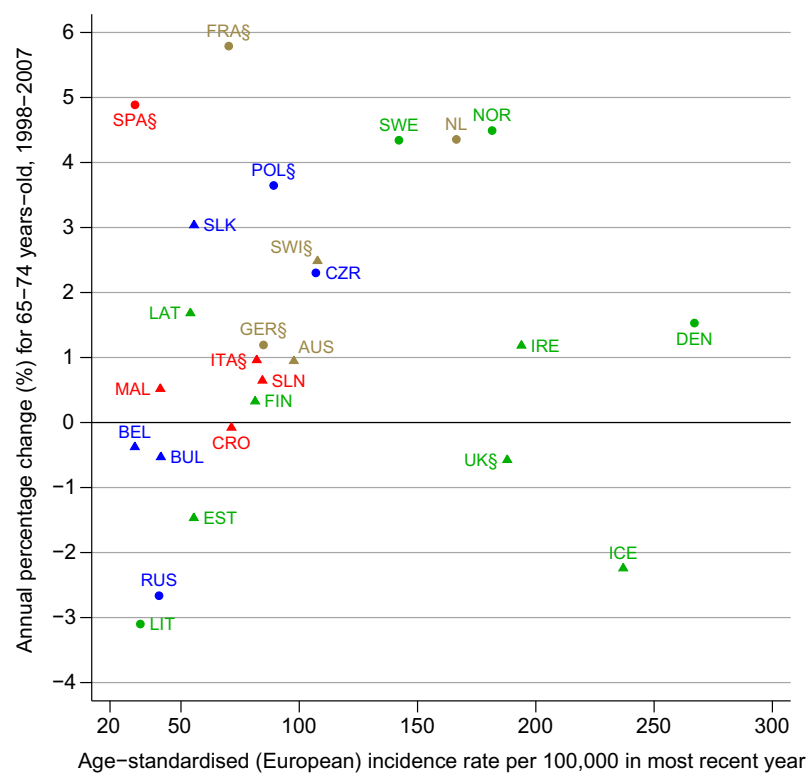

Fig. 4b. Average annual percentage change (AAPC) between 1998 and 2007 (except 1996-2005 for Spain) and age-standardised (European) incidence rates (ASR) of the most recent year of lung cancer in women aged 65 to 74 . Dots indicate statistically significant AAPC $(p \leqslant 0.05)$; triangles indicate non-significant AAPC. Colours indicate European regions: Central and eastern (blue), northern (green), southern (red) and western (brown). § Regional registries.

attributable fraction $\left(\mathrm{AF}_{\mathrm{p}}\right)$ due to cigarette smoking, $82 \%$ and $84 \%$ respectively, in the EPIC study [6].
Therefore, trends in both lung and laryngeal cancers may be largely explained by historical trends in tobacco use. For other cancers however, the $\mathrm{AF}_{\mathrm{p}}$ is smaller, and other factors such as alcohol [14], infections [15] and diet [16] may also be important in determining trends in incidence. Although smoking would undoubtedly contribute to additional new cases, it would not be wise to ascribe changes in incidence of these cancers primarily to changes in tobacco use. This study is hence confined to cancer sites where at least $30 \%$ of the new cases are due to cigarette smoking $\left(\mathrm{AF}_{\mathrm{p}}>30 \%\right)$ based on the findings of the EPIC study [6]. The eligible cancer sites (and corresponding ICD-10 codes) are: Oral cavity and Pharynx (C00-14), Oesophagus (C15), Larynx (C32) and Lung, bronchus, trachea (C33-34). An exception was made for cancer of the lower urinary tract (C65-C68); while up to half of the cases are attributed to smoking, we excluded this site because different and changing classification/coding practices [17] during the study period render international comparisons difficult. Stomach and colorectal cancer incidence are examined by Arnold et al. [18].

We restricted this study to age group 35-74 to analyse larger, more stable rates. Annual truncated age-standardised incidence rates (ASR) were calculated for each country by sex, using the European standard population [19]. To graphically summarise the trends, locally weighted regression (Lowess) curves were fitted to provide smoothed lines through the scatterplot of ASRs by calendar period. A bandwidth of 0.3 was used, i.e. $30 \%$ of the data was used in smoothing each point, except for female oesophageal and laryngeal trends, where $50 \%$ of the data was used because of the random fluctuations inherent in the small numbers involved. Rates are plotted on a log scale. Of note, for each cancer, the incidence scale is adapted to the range in incidence across the continent and varies by sex.

Changes in incidence rates were quantified for age groups 35-64, 65-74 and 35-74, for the 1998-2007 period (except Spain, for which 1996-2005 was used) through average annual percentage change (AAPC) and corresponding $95 \%$ confidence intervals [C.I.] based on the model from Clegg et al. [20]. AAPCs were estimated using the Joinpoint Regression Program (version 3.5.3) from the Surveillance Research Program of the US National Cancer Institute [21], and we used the number of cases as the dependent variable, calendar year as the independent variable, and the Poisson variance of the person-years at risk.

The proportions of adenocarcinomas (AdC) and squamous cell carcinomas (SCC) among oesophageal cancers for 1998-2002 were extracted from CI5 volume IX [9].

To illustrate the association between smoking and lung cancer incidence, and to further clarify the stage of the smoking epidemic [22], we plotted the national 


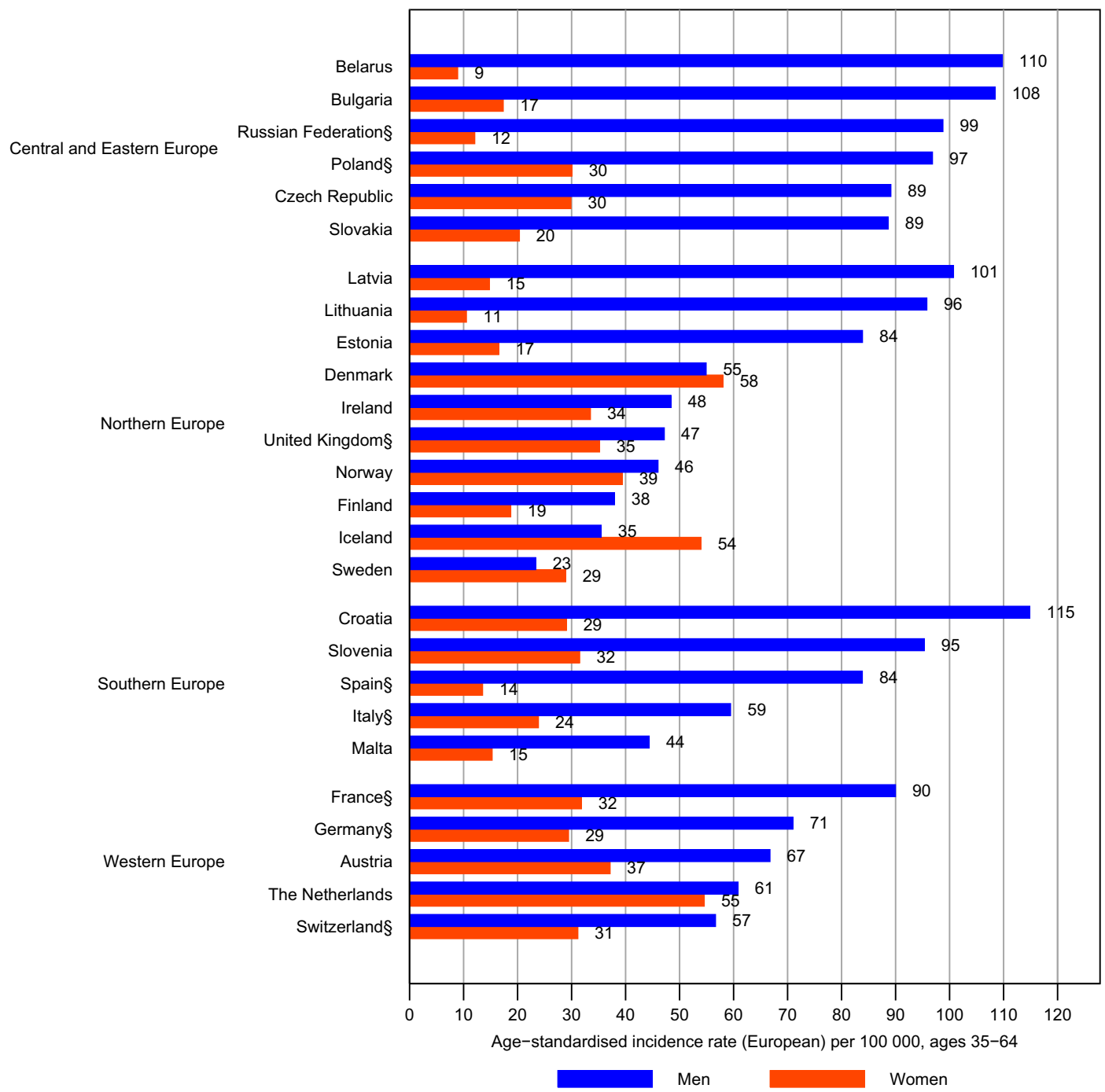

Fig. 5. Age-standardised (European) lung cancer incidence rates per 100,000 in men and women aged 35-64, in European countries, by region (2006-2008).

prevalence of daily smokers aged 15 and above and the national or regional lung cancer incidence rates for ages 35 and above, for the maximum time period available in EUREG and CI5plus databases (since 1955 for Denmark). The percentage of adult daily smokers was extracted from the Organisation for Economic Co-operation and Development [23] and the World Health Organization (WHO) [24] databases. In each of the four regions, for illustrative purposes, we selected one country with a long series of smoking prevalence and lung cancer incidence data.

\section{Results}

\subsection{Lung cancer}

Lung cancer incidence for men aged 35-74 differed markedly between countries, being highest in Belarus (161 cases per 100,000 in 2007) and lowest in Sweden
(40 cases per 100,000 in 2009), in the most recent period (Fig. 1). In most European countries, rates for men have decreased since the early 1990s, with the exception of Norway, Finland, Spain and France, where rates have remained broadly stable (Fig. 1). Over the 1998-2007 period, a significant decline in lung cancer incidence rates in men was observed in 14 of the 26 countries in middle ages (35-64 years old) and 15 countries in older ages (65-74 years old) (Figs. $2 \mathrm{a}$ and $2 \mathrm{~b}$ and Appendix Table 1). The declines were stronger in older men. In the figure presenting the recent incidence rate versus the 1998-2007 AAPC in middle-aged men (Fig. 2a), the countries were clustered by region: in northern European countries (but Baltic countries), lung cancer incidence rates were low and stable. Rates were intermediate and declining in western European countries, and high and declining in central and eastern European and Baltic countries. Rates in southern European countries did not have a uniform behaviour. 


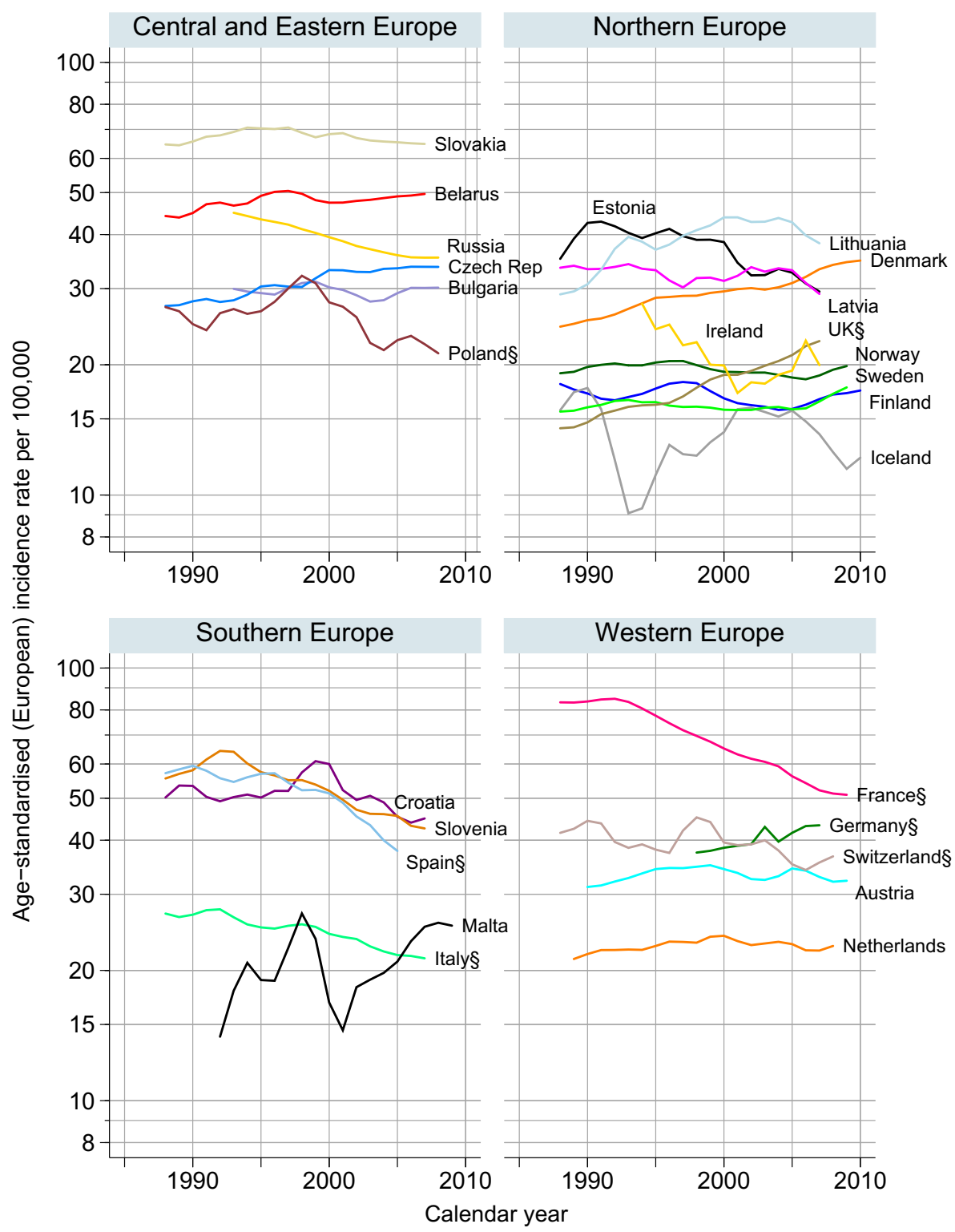

Fig. 6. Trends in age-standardised (European) oral cavity and pharyngeal cancer incidence in men aged 35-74 by country and region, from 1988 to the most recent year available (2005-2010). § Regional registries.

Among women, in the most recent period, the highest incidence rates were observed in Iceland and Denmark, with rates of 95 and 93 per 100,000 in 2010, respectively, as well as in the Netherlands (71 cases per 100,000 in 2007). Denmark appears as having a higher rate than Iceland in the graph (Fig. 3) due to smoothing. In the same period, the lowest female rates were in Belarus and Lithuania (13 cases per 100,000 in 2007). In contrast to the decreasing trends observed in men, among women rates of lung cancer by age group have increased over time (Figs. $4 \mathrm{a}$ and $4 \mathrm{~b}$ and Appendix Table 1), with the notable exceptions of the declines in older Russian and Lithuanian women in 1998-2007. Very recently (after 2005), early signs of stabilisation could be detected in women aged 35-74 in central and eastern Europe, northern Europe, Switzerland and Malta (Fig. 3). Fig. 4a (incidence rate versus AAPC in middle-aged women) showed regional clusters of countries: moderate increases in lung cancer incidence in northern countries (but stable in Baltic countries and Iceland), upper high and increasing incidence rates in western countries, low to intermediate rates with strong increases in southern Europe (but in Italy) and finally low to intermediate rates in central and eastern Europe.

Due to the convergence of the trends by sex, the male-to-female ratio has decreased during the last 20 years. Noticeably, in the most recent years (20062008), the highest male (aged 35-64) rates were found where the lowest female rates were: in central and eastern Europe, the Baltic countries and some southern European countries. Conversely, the lowest male rates and the highest female rates are found in northern 


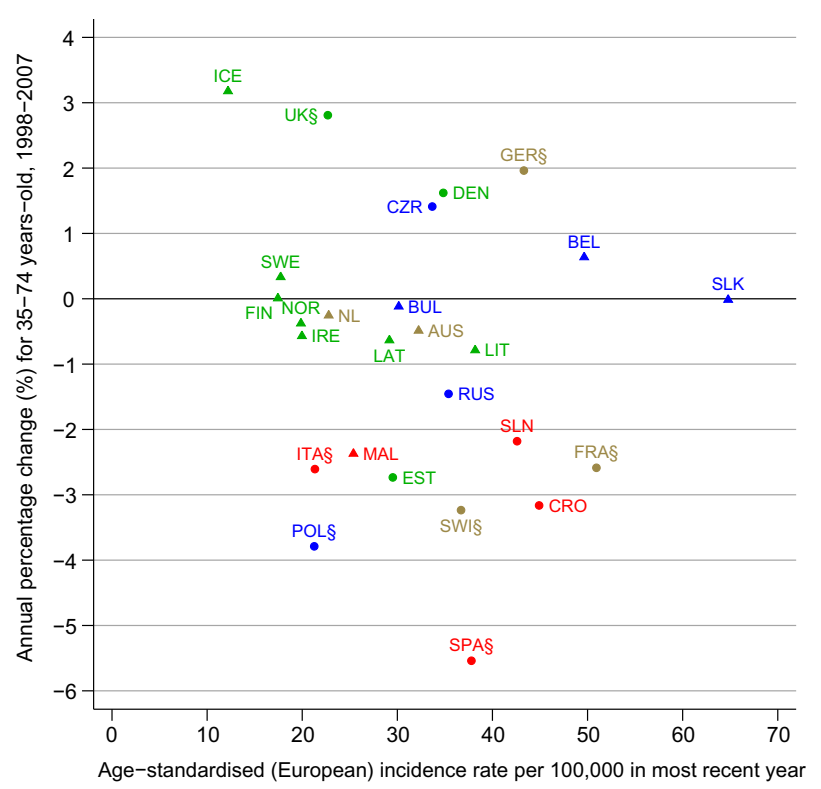

Fig. 7. Average annual percentage change (AAPC) between 1998 and 2007 (except 1996-2005 for Spain) and age-standardised (European) incidence rates (ASR) of the most recent year of oral cavity and pharyngeal cancer in men aged 35-74. Dots indicate statistically significant AAPC $(p \leqslant 0.05)$; triangles indicate non-significant AAPC. Colours indicate European regions: Central and eastern (blue), northern (green), southern (red) and western (brown). § regional registries.

Europe (excepting the Baltic countries) (Fig. 5). The sex ratio was closest to 1 in northern countries, with incidence even higher in women than in men in Denmark, Sweden and Iceland, among people aged 35-64 (Fig. 5).

\subsection{Oral cavity and pharyngeal cancer}

Within Europe, incidence of cancers of the oral cavity and pharynx among men in the most recent period varied almost sixfold, from 12 (in Iceland in 2010) to 64 (in Slovakia 2007) per 100,000 (Fig. 6). During the 1998 2007 decade, rates among men were stable in most countries in northern, western and central and eastern Europe (Fig. 7 and Appendix Table 2). In southern European countries (Croatia, Italy, Slovenia and Spain), as well as in other countries (Russia, France, Estonia, Switzerland and Poland), declines were consistently observed. In the same period, rates in women were very low in the former Soviet countries, e.g. in Belarus and Lithuania (4 and 5 per 100,000 respectively, in 2007), and were highest in western Europe, e.g. in Switzerland (17 per 100,000 in 2008) (Fig. 8). In women, rates stabilised or increased over the 1988-2007 period, with the highest increase in the Czech Republic (average increase of $6.4 \%$ per year, [95\% C.I. 4.0; 8.9]) (Fig. 9 and by age group in Appendix Table 2). While incidence rates were higher in men compared to women throughout the study period, as a consequence of the converging male and female incidence trends, the male-to-female ratio has decreased during the last 20 years. In 2006-2008, this ratio ranged from 12.6 in Belarus to 1.3 in Iceland.

\subsection{Laryngeal cancer}

In the most recent period, incidence of cancer of the larynx among men 35-74 was lowest in northern European countries (excluding the Baltic countries) and highest in central and eastern Europe, Baltic countries, Spain and Croatia: rates ranged from 4 per 100,000 in Sweden in 2009 to 30 per 100,000 in Bulgaria in 2008 (Fig. 10). Rates tended to decline in most countries (Figs. 10 and 11, and by age group in Appendix Table 3), with the greatest declines observed among men in Iceland and Poland (Average Annual Percentage Change (AAPC) of -13.7 [95\% C.I. $-23.3 ;-2.9$ ] and -6.7 $[-8.8 ;-9.4]$, respectively). In women, the incidence rates of laryngeal cancer were rather low, ranging from 0.5 to 2 per 100,000 in Belarus in 2007 and the Netherlands in 2008, respectively (Fig. 12). Although the patterns were somewhat erratic due to the low number of cases, there was a suggestion of an increase over the 1998-2007 decade in middle-aged women and a decrease at older ages (Appendix Table 3). The figures presenting the recent incidence versus AAPC (Fig. 11 and Appendix Fig. 1) revealed regional clusters of countries (with Baltic countries included in the central and eastern European countries' cluster, in men).

\subsection{Oesophageal cancer}

The variation in recent incidence of oesophageal cancer among men was fivefold, with incidence highest in the Netherlands (24 per 100,000 in 2008) and lowest in Malta (5 per 100,000 in 2009) (Fig. 13). Over the 1998-2007 period, in men aged 35-74, in general, countries in the northern half of Europe have seen increases in oesophageal cancer incidence (with the highest increase in the Netherlands: AAPC of 3.5 [95\% C.I. 2.8; 4.3]), while countries in the southern half saw declines in incidence (AAPC greater than -3.0 in France, Spain and Italy) (Appendix Fig. 2). The increases were most pronounced in middle-aged men (AAPCs of 4.4 in the Netherlands [95\% C.I. 3.1; 5.7], 4.2 in Norway [95\% C.I. 0.7; 7.8], and 4.1 in Finland [95\% C.I. 0.6; 7.8] in men aged 3564 years) (Appendix Table 4). The male-to-female ratio was higher for oesophageal cancer relative to other smoking-related cancers in this study, ranging from 2.7 in Ireland to 20.8 in Belarus in 2006-2008. Because of the random fluctuations inherent in the small numbers involved, it is difficult to discern trends in women. However, incidence rates appeared to have increased over the whole study period in most countries in western, central and eastern Europe in women aged 35-74 (Fig. 14), with the exception of a decline in Russia. Over the 1998-2007 period, in women, increases were significant only in 


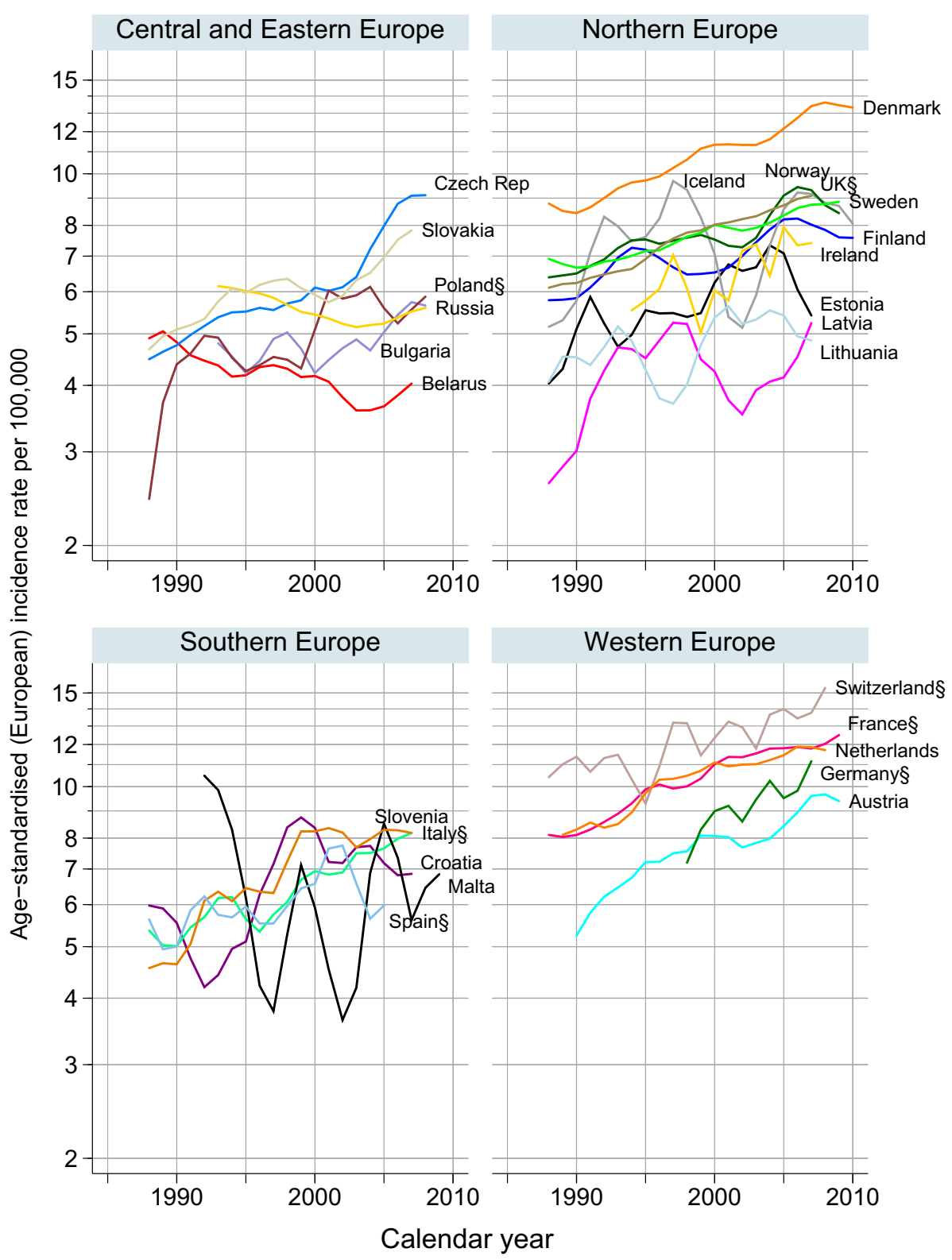

Fig. 8. Trends in age-standardised (European) oral cavity and pharyngeal cancer incidence in women aged 35-74 by country and region, from 1988 to the most recent year available (2005-2010). § Regional registries.

Iceland, Germany, Denmark and the Netherlands (Appendix Fig. 3).

Table 2 presents the proportion of the two main histological subtypes of oesophageal cancer, SCC and AdC, by country and by sex, in 1998-2002. In men, the majority of the cases were SCC. Less than $10 \%$ of the cases were $\mathrm{AdC}$ in central and eastern Europe (except in Czech Republic), the Baltic countries, Croatia and Slovenia. In the other countries of northern Europe, and in the Netherlands and Malta, AdC cases were more frequent than SCC. In women, SCC always represented the majority of the cases, except in Iceland and Latvia. The highest proportions of SCC were found in Sweden, Switzerland, Finland, France and Estonia, ranging from $73 \%$ to $82 \%$.

\subsection{Temporal trend of cigarette smoking and lung cancer incidence}

National smoking prevalence (daily smokers aged 15 and above) and age-standardised lung cancer incidence in adults (aged 35 and above) are plotted by sex in Figs. 15a and 15b, for four selected countries, one in each European region: Czech Republic (central and eastern Europe), Denmark (northern Europe), Italy (southern Europe) and France (western Europe). Although historically in those four countries the highest reported prevalence in Europe was as high as 70\% (e.g. in Danish men circa 1967), the highest current smoking prevalence was $29 \%$, in French men. In men, the decline in smoking prevalence was reflected in a later decline or stabilisation 


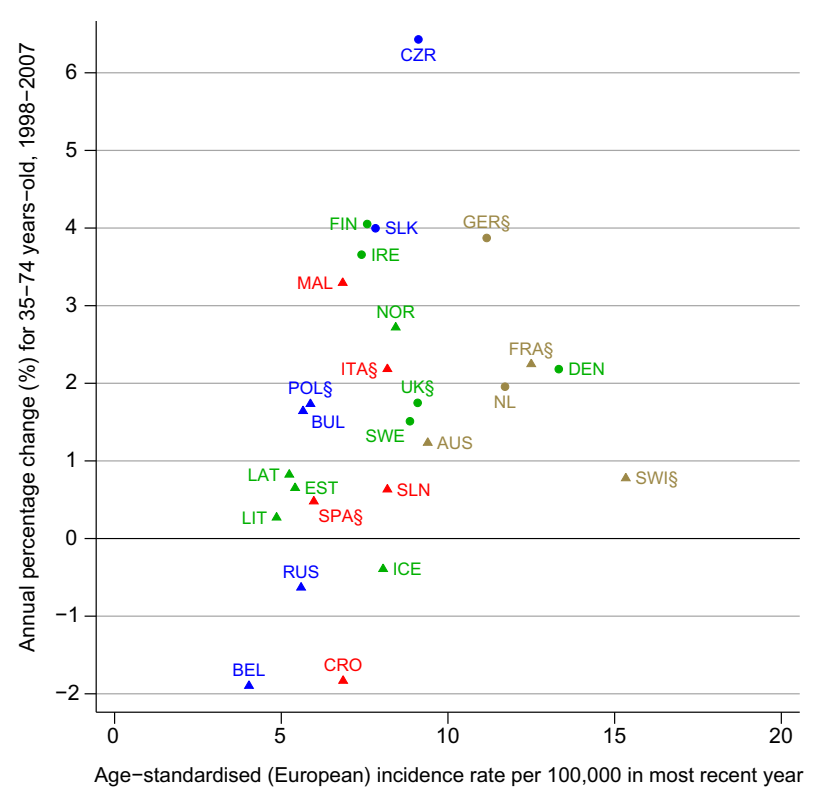

Fig. 9. Average annual percentage change (AAPC) between 1998 and 2007 (except 1996-2005 for Spain) and age-standardised (European) incidence rates (ASR) of the most recent year of oral cavity and pharyngeal cancer in women aged 35-74. Dots indicate statistically significant AAPC $(p \leqslant 0.05)$; triangles indicate non-significant AAPC. Colours indicate European regions: Central and eastern (blue), northern (green), southern (red) and western (brown). § Regional registries.

(Denmark, France) in the lung cancer incidence, with a two- to three-decade lag time. In women, smoking prevalence has been increasing in France since the 1960s, but remained stable in the Czech Republic since the mid-1980s and in Italy since the 1980s. Conversely, prevalence has markedly declined over time in Denmark, especially since the late 1990 s, with current prevalence of smokers at $20 \%$ among Danish women. In contrast to the temporal trend in men, lung cancer incidence continued to increase in women in the Czech Republic, Italy and France. The high incidence in Denmark (110 cases per 100,000 in 2010) has stabilised very recently, four decades after the peak of smoking prevalence.

\section{Discussion}

There remained large but changing variation in the incidence rates of tobacco-related cancers. Generally, male rates have been declining in lung, oral cavity and pharyngeal and laryngeal cancers, while female rates have been increasing in lung, oral cavity and pharyngeal cancers. In lung and laryngeal cancers, rates were highest in central and eastern Europe, southern Europe and the Baltic countries (in men). With respect to oesophageal cancer, mixed trends emerged.

\subsection{Lung cancer}

These analyses reveal that the gap between male and female lung cancer incidence is narrowing, particularly in northern and western Europe, with lung cancer rates in women aged 35-64 in 2006-2008 even higher than rates in men in Denmark, Iceland and Sweden. This phenomenon has also been observed in the Netherlands since the mid-1990s in women $<50$ years old [25]. In southern Europe, declines in male incidence were also reported by Znaor et al. in central Serbia over the 1999-2008 period [26]. While the peak of lung cancer cases seems to have been reached in men, as already reported by Malvezzi et al. [27], our analyses indicate that it has not yet been reached in women. It was estimated that, in Europe, in 2012, lung cancer - the majority of cases of which are attributable to smoking - was the most commonly diagnosed cancer in 15 countries and the second most common cancer in 13 further countries in men, and ranked second in three countries among women (Albania, Iceland and the UK). This neoplasm was estimated to be the most frequent cause of death by cancer in men in all European countries, with the exception of Sweden. In women, lung cancer surpassed breast cancer mortality in 12 of the 40 countries of the European region [7]. Consequently, the pattern of the cancer burden in women in Europe is approaching the cancer burden in men. Tobacco certainly plays a major role $\left(\mathrm{AF}_{\mathrm{p}}\right.$ of $\left.82 \%\right)$, but occupational exposure (such as asbestos [28]) and environmental exposures also account for a small proportion of the lung cancer cases, possibly explaining some of the observed between-country differences in rates.

\subsection{Oral cavity and pharyngeal cancers}

Although oral cavity and pharyngeal cancers are strongly related to smoking - with a cumulative risk among lifelong male smokers around 16 times higher than in never smokers - [29] the trends in oral cavity and pharyngeal cancers differ noticeably from those of lung cancer. In particular, male rates have been increasing or remained stable in some countries while lung cancer incidence rates have declined (e.g. Czech Republic, Denmark, the UK and the Netherlands). This suggests that other detrimental risk factors, such as alcohol [14] and human papillomavirus (HPV) [15] may substantially modify the trends. Conversely, diets rich in fruit and vegetables may prevent upper aerodigestive tract cancers [30]. For oral cavity cancer, the population attributable risk is $22 \%$ for tobacco alone and $40 \%$ for tobacco in combination with alcohol [14]. According to the WHO, alcohol consumption has been increasing in Czech Republic and Denmark from around $9 \mathrm{~L}$ of pure alcohol per year per person aged $15+$ to $15 \mathrm{~L}$ and from $7 \mathrm{~L}$ to 11 , respectively, over the 1960-2010 period [24]. This may partly explain the increase in the number of new oral and pharyngeal cancer patients. Conversely, the highest levels of consumption in Europe used to be around $25 \mathrm{~L}$ in France, $18 \mathrm{~L}$ in Italy, $14 \mathrm{~L}$ in Spain at the beginning of the 1960's, but 12, 6 and $10 \mathrm{~L}$ respectively in 2010 


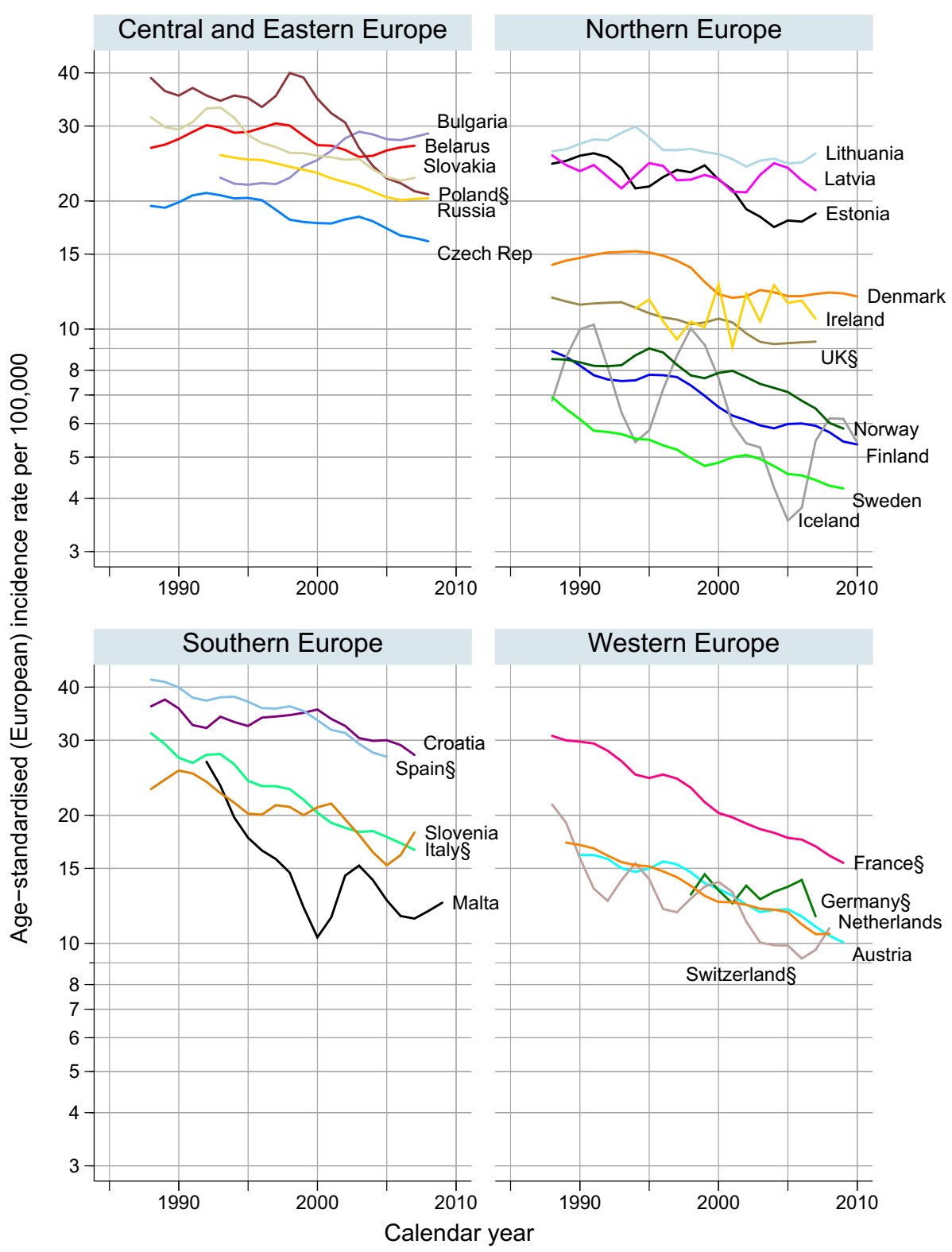

Fig. 10. Trends in age-standardised (European) laryngeal cancer incidence in men aged 35-74 by country and region, from 1988 to the most recent year available (2005-2010). § Regional registries.

[24]. As heavy alcohol consumption (i.e. $\geqslant 4$ drinks/day) is associated with an increased risk of about fivefold for oral and pharyngeal cancer [31], the decrease in average consumption may partly explain the decline in the number of new cases in those countries among men - who, on average, drink more than women. However, even lower doses of alcohol consumption (i.e. $\leqslant 1$ drink/day) increase the risk of cancer by about $20 \%$ [31]. In Europe, around year 2000, the proportion of people abstaining from drinking alcohol for the past 12 months was, on average in each country, $18 \%$ among men and $32 \%$ among women [24], putting the rest of the population at increased risk of cancer due to alcohol consumption.

The $\mathrm{AF}_{\mathrm{p}}$ for HPV varies by sub-site and also by European region. In the oropharynx, including tonsil and base of tongue, it has been estimated to range from $17 \%$ in southern Europe to $38-39 \%$ in northern, western and eastern Europe [15]. Oropharyngeal cancer incidence significantly increased among men, and at younger ages, over the 1983-2002 period, in the Netherlands, Slovakia, Denmark and the UK, thereby increasing the total number of new oral cavity and pharyngeal cancer cases. On the contrary, oropharyngeal cancer incidence declined in France and Italy [32].

\subsection{Laryngeal cancer}

Tobacco and alcohol are the main drivers behind the trends of laryngeal cancer incidence. They have a synergistic effect on this cancer [33]. In the ARCAGE 


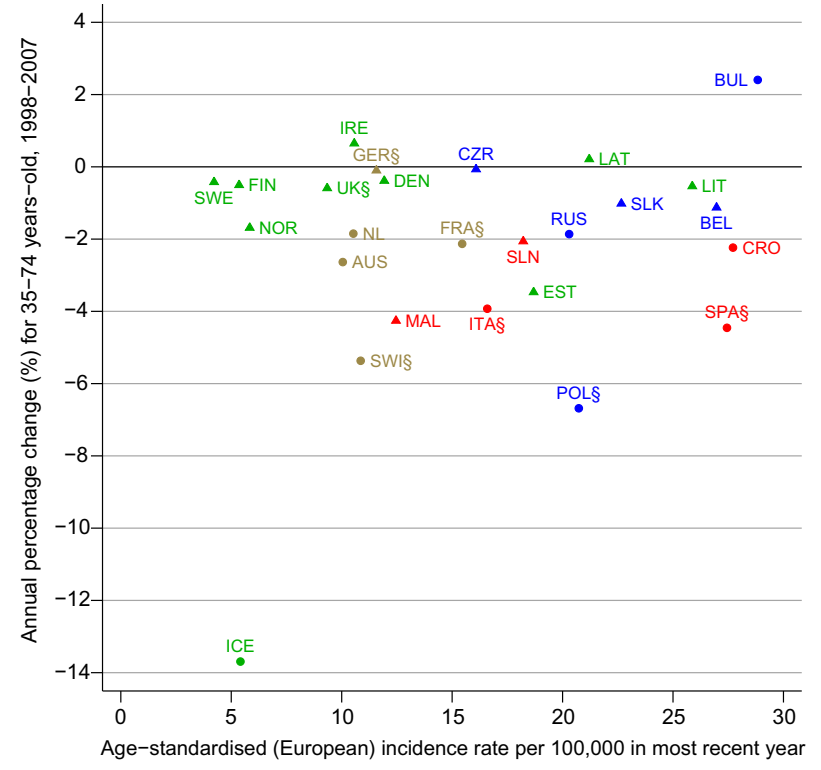

Fig. 11. Average annual percentage change (AAPC) between 1998 and 2007 (except 1996-2005 for Spain) and age-standardised (European) incidence rates (ASR) of the most recent year of laryngeal cancer in men aged 35-74. Dots indicate statistically significant AAPC $(p \leqslant 0.05)$; triangles indicate non-significant AAPC. Colours indicate European regions: Central and eastern (blue), northern (green), southern (red) and western (brown). § Regional registries.

multicentre case-control study in Europe of upper aerodigestive tract cancers, the risk estimate of hypopharyngeal/laryngeal cancer for tobacco alone was 6.7 and 1.0 for alcohol alone. However, joint exposure to tobacco and alcohol triggered an odd of 14.5 [14]. The effect of alcohol on laryngeal cancer also differs by sub-site, i.e. cancer of the supraglottis is more strongly related to alcohol consumption compared to the glottis/subglottis [34]. Finally, occupational exposures [35] may also have an impact on the incidence, and explain country-level differences.

\subsection{Oesophageal cancer}

In men, while lung cancer incidence is declining, oesophageal cancer incidence is increasing in a number of countries, particularly in the Netherlands, Finland, Belarus, Germany and the UK (ages 35-74). The difference in the observed trends for lung cancer (a proxy for past smoking behaviours) and oesophageal cancer is probably explained in part by differing risk factors for the two main subtypes of oesophageal cancer: more distantly located adenocarcinomas (AdC) and more proximal squamous cell carcinomas (SCC). They have different aetiologies. Tobacco has a stronger association with SCC, whereas gastro-oesophageal reflux disease, presence of abdominal fat and Barrett oesophagus markedly increase the risk of $\mathrm{AdC}$ of the oesophagus [36]. In our study, the proportion of AdC in men (3574 years old) was highest in the Netherlands, Ireland, the UK and Nordic countries (Table 2). Hence, in those countries, the observed increasing oesophageal cancer trends are likely to be mainly driven by risk factors other than smoking. A global assessment by Edgren et al. of the oesophageal AdC epidemic showed that it started between the 1960s (the UK) and the 1990s (Scandinavia), with considerable magnitude in variation between cancer registries [37]. Other local factors such as consumption of hot tea may also explain the marked differences for the high UK rates in both sexes [38]. As for SCC, alcohol further modifies the risk related to tobacco smoking [14]. Heavy alcohol consumption (i.e. $\geqslant 4$ drinks/day) increases the risk of oesophageal SCC about fivefold and lower (i.e. $\leqslant 1$ drink/day) doses of alcohol consumption by about $30 \%$ [31]. As in oral cavity and pharyngeal cancers, the important decline in the average alcohol consumption in some countries (e.g. France, Spain and Italy) may already have had a positive impact and could partly explain the marked decrease in incidence of oesophageal cancers in men in these countries.

\subsection{Temporal trends in cigarette smoking and lung cancer}

Recently, Thun et al. have modified the four stages of the "tobacco epidemic" [22] to accommodate gender differences [39]. Some of the variations in smoking prevalence between countries can be explained by differences in economic development. Today, on the one hand, in most European countries, men have reached the final stage, which involves falling smoking rates [40] and widening socioeconomic differences in smoking [41]. On the other hand, women are at contrasting stages within the epidemic continuum. In most of northern Europe, the tobacco epidemic in women seems to have reached the fourth stage, whereas France still lags behind and is only at the second stage, characterised by an increase in both smoking prevalence [2] and lung cancer. We also observed longer lag times between the peak of smoking prevalence and lung cancer incidence than previously reported in the USA and Japan (40 versus $15-30$ years) [42]. This could be due to differences in smoking behaviour and pattern, cigarette type, other carcinogenic exposures and susceptibility to lung cancer between countries.

The figures presenting the recent incidence rates versus the AAPC during 1998-2007 revealed regional clustering, most notably for lung and laryngeal cancers. We observed closer relationship within regions with the current burden (recent incidence rate) than with the trend (AAPC). We can infer that the today's burden in those cancer sites is the result of past regional influence, while what will happen in the future (estimated by the recent AAPC) is determined at the country level.

Some limitations of this study are worth mentioning. Firstly, seven countries had no national registration 


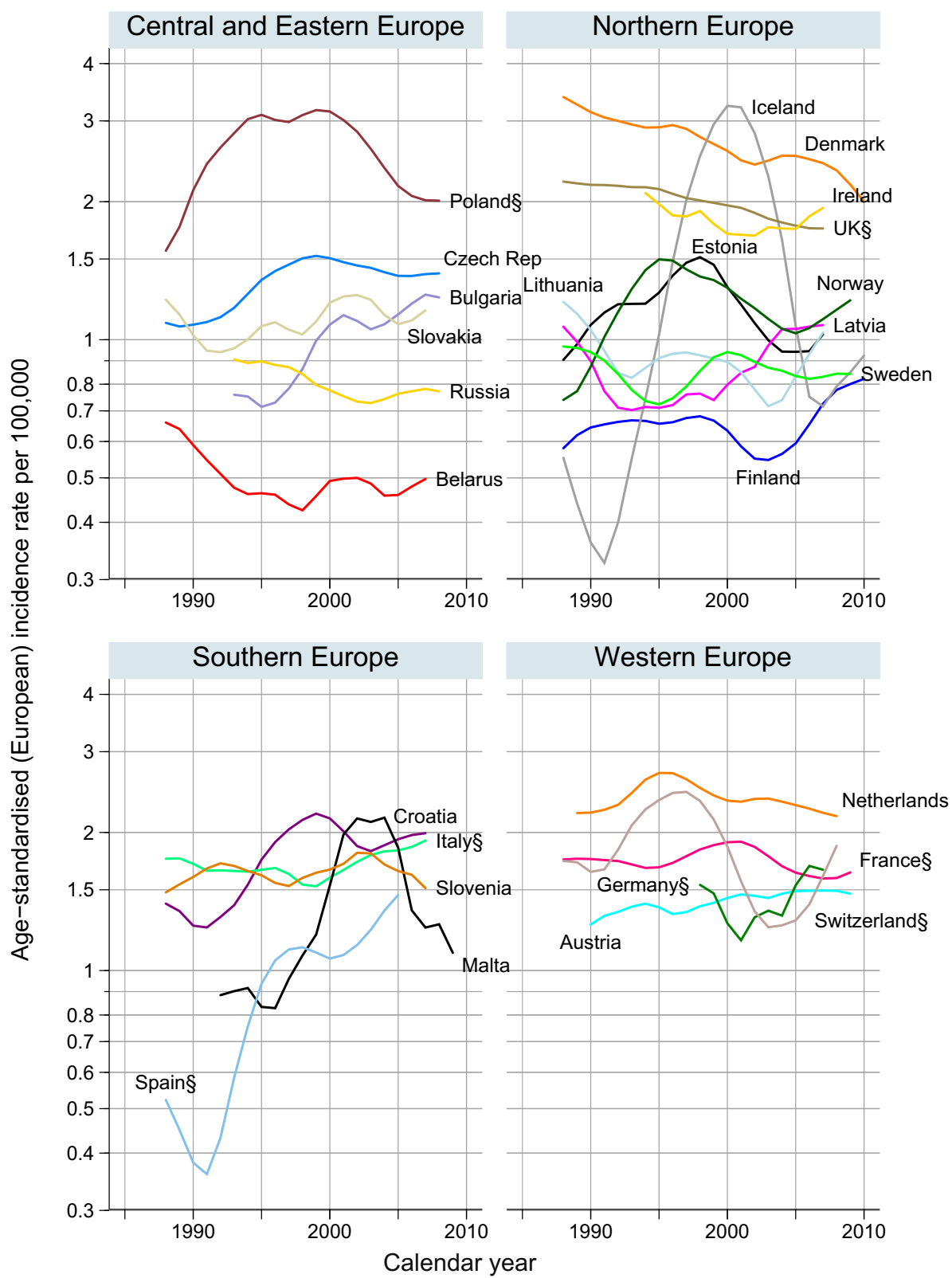

Fig. 12. Trends in age-standardised (European) laryngeal cancer incidence in women aged 35-74 by country and region, from 1988 to the most recent year available (2005-2010). § Regional registries.

coverage. We therefore combined several regional registries to obtain a proxy of the national incidence. Still, for four countries (France, Italy, Spain and Poland) the population coverage was still less than $10 \%$. In our analyses, we hence assumed that the cancer incidence in the rest of the population was equivalent to that in the areas covered by the regional registries. This may (or may not) be a reasonable assumption depending on whether the populations covered by the regional registries are representative of the national population, particularly in terms of smoking patterns. Secondly, although we chose cancer registries that had passed the most rigorous selection process of CI5 publication, data quality may have changed over time. In particular, there may have been improvements in completeness in some registries [43]. Thirdly, in an effort to standardise our analysis across countries, we assessed the changes in rates over the 1998-2007 period. As such, this method fails to capture very recent changes (after 2005), e.g. in lung cancer in women. Finally, we grouped countries by geographical region according to the United Nation (UN) classification, yet heterogeneity exists within region. For example, the rates and trends in Baltic countries (Latvia, Estonia and Lithuania) resemble more closely those of the former communist states of central and eastern Europe (including Poland, Slovakia, Russian Federation, Bulgaria, Belarus and the Czech Republic) than those of the other countries of northwestern 


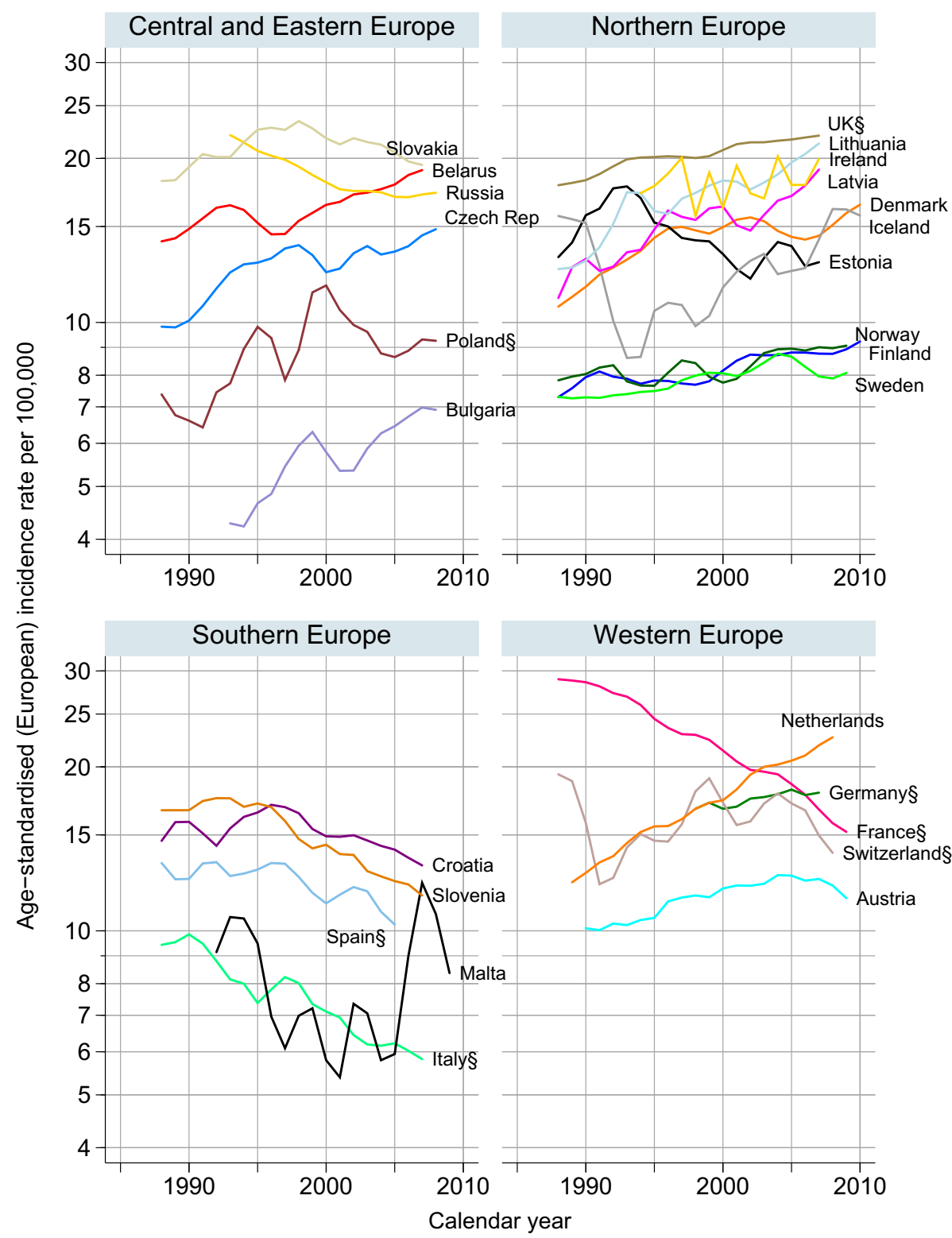

Fig. 13. Trends in age-standardised (European) oesophageal cancer incidence in men aged 35-74 by country and region, from 1988 to the most recent year available (2005-2010). § Regional registries.

Europe, possibly because of shared history and lifestyles. Likewise, incidence trends in the Netherlands, classified as being in western Europe, more closely resemble those of the UK, Ireland and Denmark.

\section{Conclusions}

Our study illustrates the impact of the economic conditions as well as successes and failures of tobacco control policies in Europe. These policies have contributed to decreasing smoking prevalence in men, but have failed thus far to prevent smoking initiation in women or to support them in quitting smoking. Implementation was far too late in central and eastern Europe and the Baltic countries. Tobacco control remains a top priority for cancer control in Europe [44]; advances in cancer therapy have not had much success in improving survival for the cancers in this study $[45,46]$. Key targets for prevention efforts should include men in central and eastern Europe [27], southern Europe and Baltic countries and young women across Europe [7]. In recognition of the heterogeneity and diversity between populations, targeted and adaptable approaches to cancer prevention are essential [47]. As the EUREG database is continuously updated with new incidence, mortality and survival data and new population-based cancer registries, it offers enormous opportunities to increase the knowledge on cancer and its control in the years to come. 


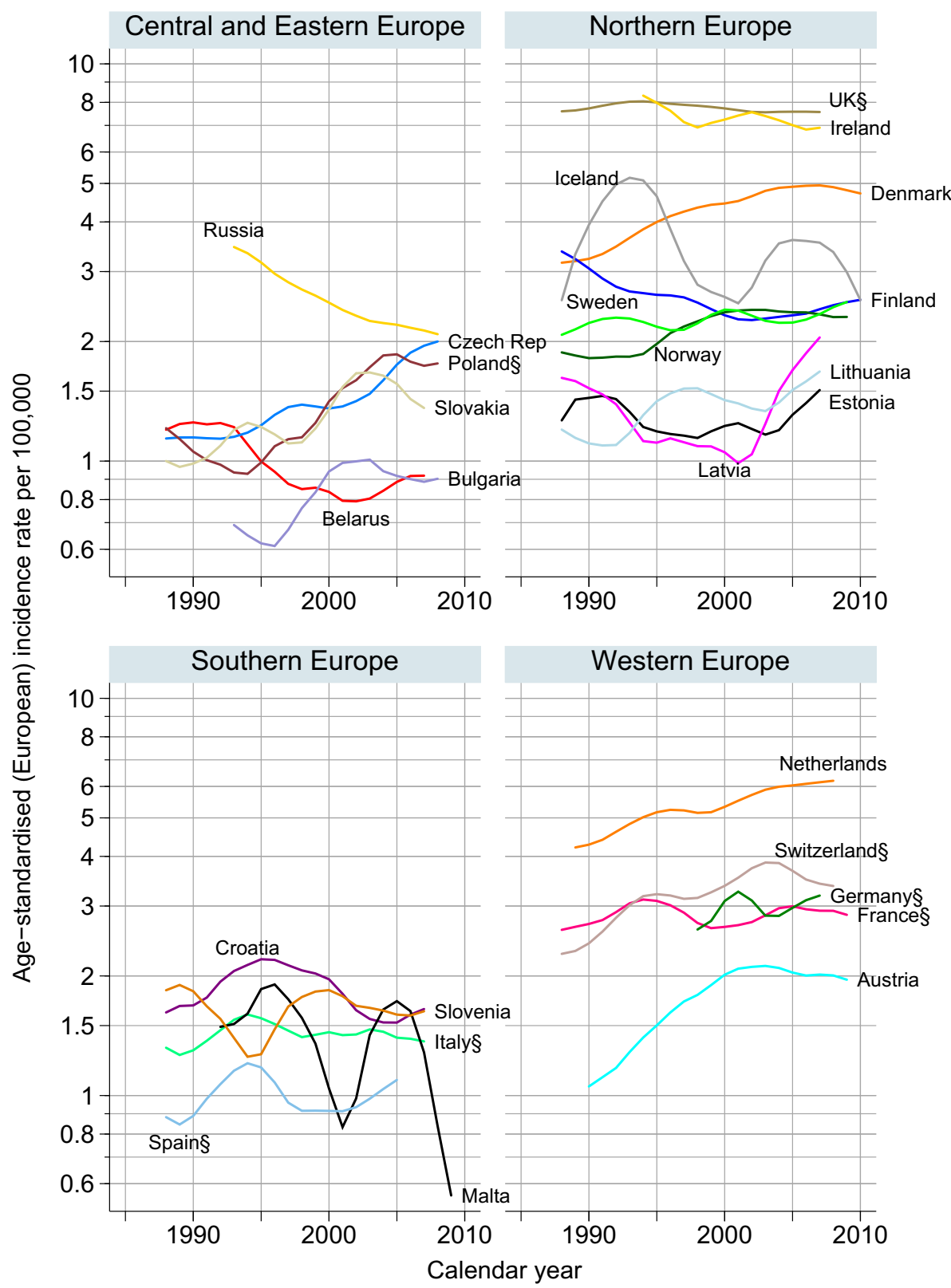

Fig. 14. Trends in age-standardised (European) oesophageal cancer incidence in women aged 35-74 by country and region, from 1988 to the most recent year available (2005-2010). § Regional registries.

\section{Sponsors}

The study sponsors were not involved in the study design, in the collection, analysis and interpretation of the data, in the writing of the manuscript and in the decision to submit the manuscript for publication.

\section{Sources of support}

The data of this study were collected within the framework of the EUROCOURSE project funded by the EU FP7 (Project number: 219453), which was led by JWC and HC. IS is supported by the Marie Curie IEF (Project number 302050). This study is partly supported by the Women in Europe against Lung Cancer and Smoking (WELAS) project funded by the European Commission, DG Sanco (Public Health Programme, Project Number: 2006 319).

\section{Conflict of interest statement}

None declared.

\section{Acknowledgements}

We thank Suzanne Moore and John Daniel for editing and Melina Arnold for her help with the time trends and AAPC figures. 
Table 2

Proportion of oesophageal cancer by main histological sub-type, by sex, in 1998-2002, ages 35-74. Source: Cancer Incidence in Five Continents Vol. IX [9].

\begin{tabular}{|c|c|c|c|c|c|}
\hline \multirow[t]{2}{*}{ Region } & \multirow[t]{2}{*}{ Country } & \multicolumn{2}{|l|}{ Men } & \multicolumn{2}{|l|}{ Women } \\
\hline & & Squamous cell carcinoma (\%) & Adenocarcinoma (\%) & Squamous cell carcinoma (\%) & Adenocarcinoma $(\%)$ \\
\hline \multicolumn{6}{|c|}{ Central \& eastern Europe } \\
\hline & Belarus & 66 & 9 & 43 & 18 \\
\hline & Bulgaria & - & - & - & - \\
\hline & Czech Republic & 56 & 23 & 55 & 18 \\
\hline & Poland $^{\mathrm{a}}$ & - & - & - & - \\
\hline & Russian Federation & 55 & 8 & 51 & 9 \\
\hline & Slovakia & 70 & 9 & 55 & 26 \\
\hline \multicolumn{6}{|c|}{ Northern Europe } \\
\hline & Denmark & 43 & 44 & 65 & 25 \\
\hline & Estonia & 82 & 5 & 82 & 0 \\
\hline & Finland & 52 & 37 & 75 & 19 \\
\hline & Iceland & 34 & 63 & 22 & 44 \\
\hline & Ireland & 34 & 54 & 64 & 24 \\
\hline & Latvia & 63 & 9 & 31 & 17 \\
\hline & Lithuania & 63 & 8 & 63 & 12 \\
\hline & Norway & 50 & 42 & 66 & 26 \\
\hline & Sweden & 46 & 47 & 73 & 23 \\
\hline & United Kingdom $^{\mathrm{a}}$ & 25 & 59 & 55 & 27 \\
\hline \multicolumn{6}{|c|}{ Southern Europe } \\
\hline & Croatia & 56 & 6 & 50 & 12 \\
\hline & Italy $^{\mathrm{a}}$ & 66 & 18 & 68 & 13 \\
\hline & Malta & 36 & 43 & 60 & 20 \\
\hline & Slovenia & 77 & 9 & 63 & 22 \\
\hline & Spain $^{\mathrm{a}}$ & 74 & 17 & 63 & 18 \\
\hline \multicolumn{6}{|c|}{ Western Europe } \\
\hline & Austria & 54 & 25 & 50 & 18 \\
\hline & France $^{\mathrm{a}}$ & 77 & 17 & 81 & 11 \\
\hline & Germany $^{\mathrm{a}}$ & 61 & 17 & 64 & 14 \\
\hline & Switzerland $^{\mathrm{a}}$ & 62 & 31 & 74 & 17 \\
\hline & The Netherlands & 36 & 56 & 58 & 33 \\
\hline
\end{tabular}

Proportions in Bulgaria and Poland are not displayed due to the low proportion of microscopically verified cases $(35 \%$ in men and $27 \%$ in women in Bulgaria, $57 \%$ and $43 \%$ in Poland Cracow and $77 \%$ and $74 \%$ in Kielce respectively). The other histological subtypes not displayed are: other specified carcinoma, Unspecified carcinoma, sarcoma, other specified morphology and unspecified morphology.

${ }^{a}$ Regional registries: France (Doubs, Herault, Isere, Haut-Rhin, Somme, Tarn); Germany (Brandenburg, Hamburg, Saxony, Mecklenburg, North Rhine-Westphalia, Saarland); Poland (Kielce, Cracow); Italy (Modena, Parma, Ragusa, Romagna, Torino, Varese); Spain (Granada, Murcia, Navarra, Tarragona); Switzerland (Geneva, St Gall-Appenzell), United Kingdom (England and Scotland).

The authors gratefully acknowledged the following cancer registries who have contributed in sharing their data needed as baseline for incidence prediction: Austria - Austrian Cancer Registry (Mrs Zielonke, Prof Hainfellner); Belarus - Belarusian Cancer Registry (Prof Okeanov); Bulgaria - Bulgarian National Cancer Registry (Dr. Dimitrova); Croatia - Croatian National Cancer Registry (Prof Znaor); Czech Republic - Czech National Cancer Registry (Dr. Holub, Dr. Toman); Estonia - Estonian Cancer Registry (Dr. Mägi); Denmark - Danish Cancer Registry (Dr. Milter, Dr. Larsen, Mrs Gjerstorff); Finland - Finnish Cancer Registry (Prof Malila); France - Doubs Cancer Registry (Dr. Woronoff), Herault Cancer Registry (Dr. Tretarre), Isere Cancer Registry (Dr. Colonna), Haut-Rhin Cancer Registry (Dr. Buemi), Somme Cancer Registry (Dr. Lapotre- Ledoux), Tarn Cancer Registry (Dr. Grosclaude); Germany - Bradenburg Cancer Registry and
Mecklenburg-Western Pomerania Cancer Registry (Dr. Stabenow), Lower Saxony Cancer Regsitry (Dr. Kieschke), Hamburg Cancer Registry (Dr. Hentschel), North Rhine-Westphalia Cancer Registry (Dr. Heidinger), Saarland Cancer Registry (Dr. Kaatsch, Mr Holleczek); Iceland - Icelandic Cancer Registry (Prof Jonasson); Ireland - National Cancer Registry Ireland (Dr. Comber); Italy - Tumour Registry of Modena (Prof Federico), Parma Cancer Registry (Dr. Michiara), Ragusa Cancer Registry (Dr. Tumino), Romagna Tumour Registry (Dr. Falcini), Turin Tunour Registry (Dr. Zanetti), Varese Tumour Registry (Dr. Crosignani); Latvia - Latvian Cancer Registry (Dr. Maurina); Lithuania - Lithuanian Cancer Registry (Dr. Smailyte); Malta - Malta National Cancer Registry (Dr. Calleja); Norway - Cancer Registry of Norway (Prof Ursin); Poland - Cracow City and District Cancer Registry (Dr. Rachtan), Kielce Regional 


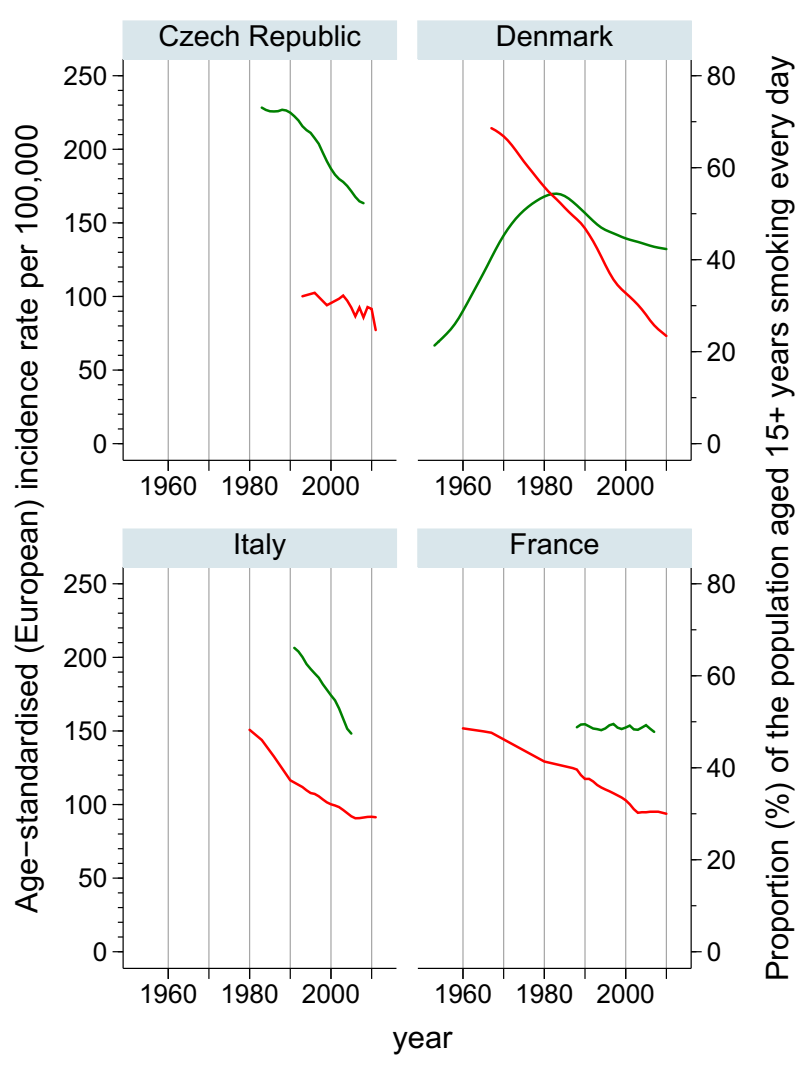

— Lung cancer incidence _ Smoking prevalence

Fig. 15a. Age-standardised (European) lung cancer incidence rates per 100,000 in men aged 35 and above and prevalence of daily smokers in men aged 15 and above in Czech Republic, Denmark, Italy and France.

Cancer Registry (Dr. Gozdz); Slovakia - Slovakia National Cancer Registry (Dr. Safaei Diba, Dr. Kaiserova); Slovenia - Cancer Registry of Republic of Slovenia (Prof Primic Žakelj); Spain - Granada Cancer Registry (Dr. Sanchez-Perez), Murcia Cancer Registry (Dr. Navarro Sánchez), Navarra Cancer Registry (Dr. Ardanaz Aicua), Tarragona Cancer Registry (Prof Peris-Bonet, Dr. Galceran); Sweden - Swedish Cancer Registry (Ms Klint, Dr. Heyman); Switzerland - Geneva Cancer Registry (Prof Bouchardy), St. Gallen-Appenzell Cancer Registry (Prof Kuehni, Dr. Ess), The Netherlands - The Netherlands Cancer Registry, Comprehensive Cancer Centre South (Dr. De Ridder-Sluiker); United Kingdom - Eastern England, Northern and Yorkshire Cancer Registry, North West Cancer Intelligence Service, Oxford Cancer Intelligence Unit, South West Cancer Registry (Mr David Meecham, Dr. Gill Lawrence, Dr. Stiller); Russian Federation - Russian Centre for technologic information and epidemiological studies in the field of oncology.

\section{Appendix A. Supplementary data}

Supplementary data associated with this article can be found, in the online version, at http://dx.doi.org/ 10.1016/j.ejca.2013.10.014.

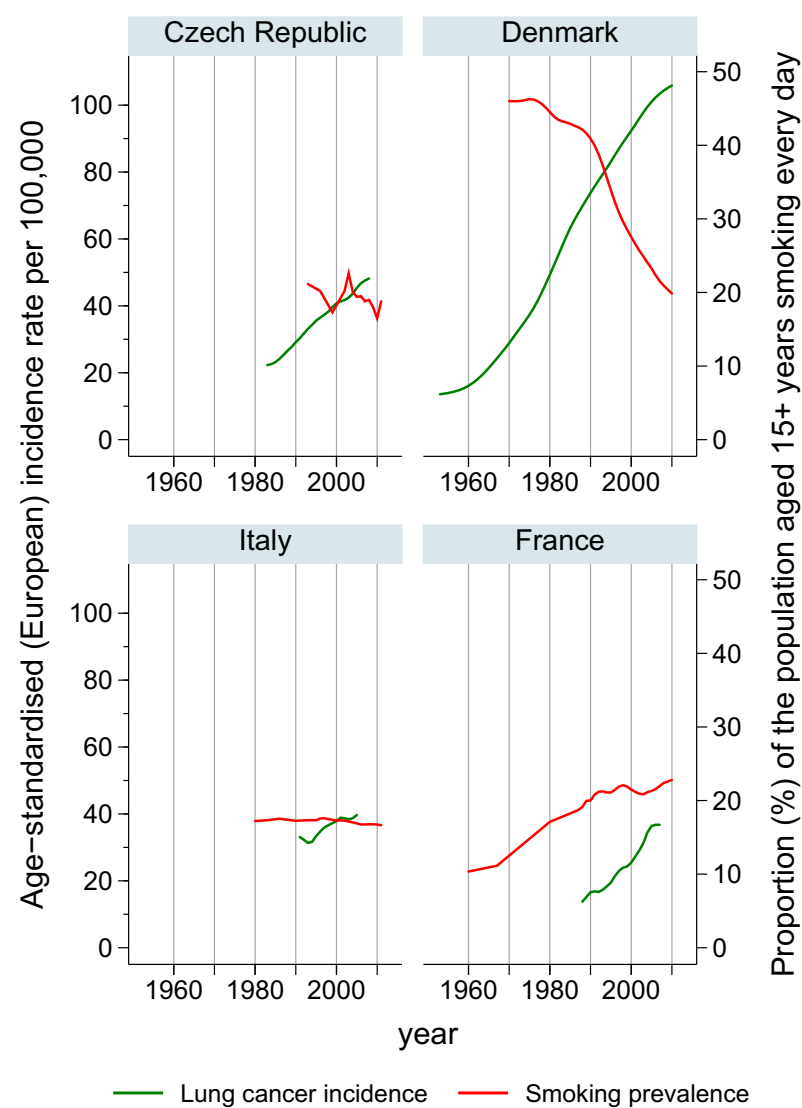

Fig. 15b. Age-standardised (European) lung cancer incidence rates per 100,000 in women aged 35 and above and prevalence of daily smokers in women aged 15 and above in Czech Republic, Denmark, Italy and France.

\section{References}

[1] Doll R. The first reports on smoking and lung cancer. In: Lock SR, Tansey EM, editors. Ashes to ashes: the history of smoking and health, vol. 46. Rodopi: Amsterdam; 1998. p. 130-40.

[2] Graham H. Smoking prevalence among women in the European community 1950-1990. Soc Sci Med 1996;43(2):243-54.

[3] Gilmore A, Pomerleau J, McKee M, Rose R, Haerpfer CW, Rotman D, et al. Prevalence of smoking in 8 countries of the former Soviet Union: results from the living conditions, lifestyles and health study. Am J Public Health 2004;94(12): 2177-87.

[4] Helasoja VV, Lahelma E, Prattala RS, Patja KM, Klumbiene J, Pudule I, et al. Determinants of daily smoking in Estonia, Latvia, Lithuania, and Finland in 1994-2002. Scand J Public Health 2006;34(4):353-62.

[5] Secretan B, Straif K, Baan R, Grosse Y, El Ghissassi F, Bouvard $\mathrm{V}$, et al. A review of human carcinogens-Part E: tobacco, areca nut, alcohol, coal smoke, and salted fish. Lancet Oncol 2009;10(11):1033-4.

[6] Agudo A, Bonet C, Travier N, Gonzalez CA, Vineis P, Bueno-deMesquita HB, et al. Impact of cigarette smoking on cancer risk in the European prospective investigation into cancer and nutrition study. J Clin Oncol 2012;30(36):4550-7.

[7] Ferlay J, Steliarova-Foucher E, Lortet-Tieulent J, Rosso S, Coebergh JW, Comber H, et al. Cancer incidence and mortality patterns in Europe: estimates for 40 countries in 2012. Eur J Cancer 2013;49(6):1374-403. 
[8] European Cancer Observatory: Cancer Incidence, Mortality, Prevalence and Survival in Europe. European Network of Cancer Registries, International Agency for Research on Cancer. [Internet]. [cited 02/04/2013]. Available from: http://eco.iarc.fr.

[9] Curado MPE, Shin B, Storm HR, Ferlay H, Ferlay M, Heanue $\mathrm{JM}$, et al., editors. Cancer incidence in five continents, vol. IX. Lyon, France: IARC Scientific Publications; 2007.

[10] Cancer Incidence in Five Continents, vol. I-IX: IARC CancerBase No. 9. Lyon, France: International Agency for Research on Cancer; 2010. Available from: http://ci5.iarc.fr [Internet].

[11] Engholm G FJ, Christensen N, Johannesen TB, Klint Å, Køtlum JE, Milter MC et al. NORDCAN: cancer incidence, mortality, prevalence and survival in the Nordic countries, Version 5.3. Association of the Nordic Cancer Registries. Danish Cancer, Society; 25.04.2013.

[12] Chissov VI, Starinsky VV, Petrova GV. Malignant neoplasms in Russia in 2008 (morbidity and mortality). Moscow, PA: Hertzen Moscow Research Oncological Institute; 2010.

[13] United Nations. World Population Prospects: The 2008 Revision, Highlights. Department of Economic and Social Affairs, Population Division 2009.

[14] Anantharaman D, Marron M, Lagiou P, Samoli E, Ahrens W, Pohlabeln H, et al. Population attributable risk of tobacco and alcohol for upper aerodigestive tract cancer. Oral Oncol 2011;47(8):725-31.

[15] de Martel C, Ferlay J, Franceschi S, Vignat J, Bray F, Forman D, et al. Global burden of cancers attributable to infections in 2008: a review and synthetic analysis. Lancet Oncol 2012;13(6): $607-15$.

[16] Key TJ, Allen NE, Spencer EA, Travis RC. The effect of diet on risk of cancer. Lancet 2002;360(9336):861-8.

[17] Parkin DM, Whelan SL, Ferlay J, Teppo L, Thomas DB, editors. Cancer incidence in five continents, vol. VIII. Lyon, France: IARC Scientific Publications; 2002.

[18] Arnold M, Karim-Kos HE, Coebergh JW, Byrnes G, Antilla A, Ferlay J, et al. Recent trends in incidence of five common cancers in 26 European countries since 1988: analysis of the European Cancer Registry database. Eur J Cancer 2015;51:1164-87.

[19] Waterhouse J, Muir CS, Correa P, Powell J, editors. Cancer incidence in five continents, vol. III. Lyon, France: IARC Scientific Publications; 1976.

[20] Clegg LX, Hankey BF, Tiwari R, Feuer EJ, Edwards BK. Estimating average annual per cent change in trend analysis. Stat Med 2009;28(29):3670-82.

[21] National Cancer Institute. Surveillance, epidemiology, and end results (SEER) program. Joinpoint regression program. Available from: http://srab.cancer.gov/joinpoint/.

[22] Lopez AD, Collishaw NE, Piha T. A descriptive model of the cigarette epidemic in developed countries. Tob Control 1994:3.

[23] OECD health data: non-medical determinants of health. OECD health statistics (database) [Internet]. Available from: http:// stats.oecd.org/index.aspx?DataSetCode=HEALTH_STAT; 2013 [accessed 02.05.13].

[24] World Health Organisation. Global information system on alcohol and health [Internet]. Available from: http://apps.who.int/gho/data/node.main; 2013 [accessed 10.05.13].

[25] Karim-Kos HE, Janssen-Heijnen ML, van Iersel CA, van der Meer RM, de Vries E, Coebergh JW. The beginning of the end of the lung cancer epidemic in Dutch women? Int J Cancer 2008;123(6):1472-5.

[26] Znaor A, van den Hurk C, Primic-Zakelj M, Agius D, Coza $\mathrm{D}$, Demetriou $\mathrm{A}$, et al. Cancer incidence and mortality patterns in South Eastern Europe in the last decade: gaps persist compared with the rest of Europe. Eur J Cancer 2013;49(7):1683-91.
[27] Malvezzi M, Bosetti C, Rosso T, Bertuccio P, Chatenoud L, Levi $F$, et al. Lung cancer mortality in European men: trends and predictions. Lung Cancer 2013;80(2):138-45.

[28] McCormack V, Peto J, Byrnes G, Straif K, Boffetta P. Estimating the asbestos-related lung cancer burden from mesothelioma mortality. Br J Cancer 2012;106(3):575-84.

[29] Bosetti C, Gallus S, Peto R, Negri E, Talamini R, Tavani A, et al. Tobacco smoking, smoking cessation, and cumulative risk of upper aerodigestive tract cancers. Am J Epidemiol 2008;167(4):468-73.

[30] Bravi F, Edefonti V, Randi G, Ferraroni M, La Vecchia C, Decarli A. Dietary patterns and upper aerodigestive tract cancers: an overview and review. Ann Oncol 2012;23(12): 3024-39.

[31] Pelucchi C, Tramacere I, Boffetta P, Negri E, La Vecchia C. Alcohol consumption and cancer risk. Nutr Cancer 2011;63(7):983-90.

[32] Chaturvedi A AW, Lortet-Tieulent J, Curado MP, Ferlay J, Franceschi S, Rosenberg P et al. Worldwide trends in incidence rates for oral cavity and oropharyngeal cancers. J Clin Oncol 2013 [in press].

[33] Hashibe M, Brennan P, Chuang SC, Boccia S, Castellsague $\mathrm{X}$, Chen $\mathrm{C}$, et al. Interaction between tobacco and alcohol use and the risk of head and neck cancer: pooled analysis in the International Head and Neck Cancer Epidemiology Consortium. Cancer Epidemiol Biomarkers Prev 2009;18(2): $541-50$.

[34] La Vecchia C, Zhang ZF, Altieri A. Alcohol and laryngeal cancer: an update. Eur J Cancer Prev 2008;17(2):116-24.

[35] Menvielle G, Luce D, Goldberg P, Leclerc A. Smoking, alcohol drinking, occupational exposures and social inequalities in hypopharyngeal and laryngeal cancer. Int $\mathrm{J}$ Epidemiol 2004;33(4):799-806.

[36] Pennathur A, Gibson MK, Jobe BA, Luketich JD. Oesophageal carcinoma. Lancet 2013;381(9864):400-12.

[37] Edgren G, Adami HO, Weiderpass E, Nyren O. A global assessment of the oesophageal adenocarcinoma epidemic. Gut 2013;62:1406-14. http://dx.doi.org/10.1136/gutjnl-2012-302412.

[38] Sharp L, Chilvers CE, Cheng KK, McKinney PA, Logan RF, Cook-Mozaffari P, et al. Risk factors for squamous cell carcinoma of the oesophagus in women: a case-control study. Br J Cancer 2001;85(11):1667-70.

[39] Thun M, Peto R, Boreham J, Lopez AD. Stages of the cigarette epidemic on entering its second century. Tob Control 2012;21(2):96-101.

[40] Shafey O DS, Guindon GE. Tobacco control country profiles 2003. Atlanta, GA: American Cancer Society; 2003.

[41] Menvielle G, Boshuizen H, Kunst AE, Dalton SO, Vineis P, Bergmann MM, et al. The role of smoking and diet in explaining educational inequalities in lung cancer incidence. J Natl Cancer Inst 2009;101(5):321-30.

[42] Ito H, Matsuo K, Tanaka H, Koestler DC, Ombao H, Fulton J, et al. Nonfilter and filter cigarette consumption and the incidence of lung cancer by histological type in Japan and the United States: analysis of 30-year data from population-based cancer registries. Int J Cancer 2011;128(8):1918-28.

[43] Karim-Kos HE, de Vries E, Soerjomataram I, Lemmens V, Siesling S, Coebergh JW. Recent trends of cancer in Europe: a combined approach of incidence, survival and mortality for 17 cancer sites since the 1990s. Eur J Cancer 2008;44(10): 1345-89.

[44] Boyle P, Autier P, Bartelink H, Baselga J, Boffetta P, Burn J, et al. European code against cancer and scientific justification: third version (2003). Ann Oncol 2003;14(7):973-1005.

[45] Berrino F, De Angelis R, Sant M, Rosso S, Bielska-Lasota M, Coebergh JW, et al. Survival for eight major cancers and all 
cancers combined for European adults diagnosed in 1995-99: results of the EUROCARE-4 study. Lancet Oncol 2007;8(9):773-83.

[46] van Dijk BAC, Karim-Kos HE, Coebergh JW, Marres HAM, de Vries E. Progress against laryngeal cancer in The Netherlands between 1989 and 2010. Int J Cancer 2013. http://dx.doi.org/ 10.1002/ijc. 28388 .

[47] Coebergh JW, Martin-Moreno JM, Soerjomataram I, Renehan AG. The long road towards cancer prevention: 4 steps backward and 8 forward. Eur J Cancer 2010;46(14):2660-2. 